\title{
Der Grillenburger Sandsteinbruch am Flügel Jägerhorn (Cenomanium, Tharandter Wald, Sachsen) - historisch berühmt und geologisch verkannt
}

\section{The Grillenburg sandstone quarry at the Flügel Jägerhorn (Cenomanian, Tharandter Wald, Saxony) - historically famous and geologically misunderstood}

\author{
Birgit Niebuhr $^{1}$, Frank Haubrich², Markus Fengler ${ }^{3}$ \\ 1 Senckenberg Naturhistorische Sammlungen Dresden, Museum für Mineralogie und Geologie, Königsbrücker Landstraße 159, 01109 Dresden, \\ Deutschland; birgit.niebuhr@senckenberg.de \\ 2 Dr.-Richard-Beck-Straße 27,09599 Freiberg,Deutschland; haubrich.f@googlemail.com \\ 3 Wiesenstraße 4, 01468 Moritzburg, Deutschland; mf@kreidefossilien.de \\ Corresponding author: Birgit Niebuhr (birgit.niebuhr@senckenberg.de)
}

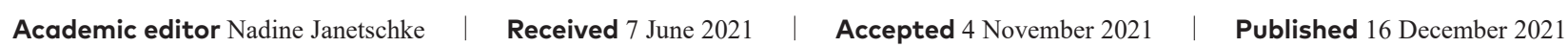

Citation: Niebuhr B, Haubrich F, Fengler M (2021) Der Grillenburger Sandsteinbruch am Flügel Jägerhorn (Cenomanium, Tharandter Wald, Sachsen) - historisch berühmt und geologisch verkannt. Geologica Saxonica 67 1-28. https://doi.org/10.3897/gs.67.e78579

\section{Zusammenfassung}

Der Steinbruch am Flügel Jägerhorn westlich von Grillenburg ist vermutlich der älteste Kreidesandsteinbruch des Tharandter Waldes, in Betrieb seit etwa 1170. Historisch belegt ist, dass beispielsweise 1225 die Goldene Pforte des Freiberger St.-Marien-Doms aus Grillenburger Sandstein gefertigt wurde. Die vom Universalgelehrten J. F. Henckel (1722) veröffentlichten Kupferstiche der fossilen Hahnenkamm-Muschel Rastellum carinatum und der Pectinide Merklinia aspera aus dem „Sandsteinbruche im Grüllenburger Walde" sind in der Literatur die bisher ältesten bekannten Abbildungen von sächsischen Kreide-Fossilien.

Im Sandsteinbruch am Flügel Jägerhorn ist als unterster Abschnitt die über $5 \mathrm{~m}$ mächtige „Werksteinbank“ aufgeschlossen, der marine Werksandstein der oberen Oberhäslich-Formation (unteres Obercenomanium), der fälschlicherweise in den letzten über 130 Jahren der kontinentalen Niederschöna-Formation (Untercenomanium) zugeordnet und als fossilfreier Dünensandstein interpretiert wurde. Die obersten 1,50-2 m der „Werksteinbank“ beinhalten neben Glaukonit auch fünf verschiedene Spurenfossilien der Skolithos-Ichnofazies, die sandig-flachmarine Ablagerungsräume charakterisiert. Es folgt die Pennrich-Formation (oberes Obercenomanium) mit dem ca. 1,50 m mächtigen plenus-Horizont und einem Transgressionskonglomerat aus bis zu $15 \mathrm{~cm}$ großen, gut gerundeten Rhyolith-Geröllen an der Basis. Zuoberst sind im Steinbruch noch 3-7 m gut gebankte, spiculitisch-glaukonitische Siltsteine erhalten.

Diese lithostratigraphische Abfolge ist typisch für das Osterzgebirge: marines Mittel- und Obercenomanium überlagert fluviatiles Untercenomanium. Die mittlere und obere Oberhäslich-Formation im Tharandter Wald - auflagernd auf der fluviatilen, mittleren Niederschöna-Formation und überlagert von der tiefermarinen Pennrich-Formation - ist etwa 20 m mächtig; als einziger cenomanzeitlicher Werksandstein der sächsischen Kreide wurden jeweils die obersten 5-7 m gebrochen. Bei Grillenburg transgredieren die Abfolgen der Oberhäslich- und Pennrich-Formation auch direkt auf den permischen Rhyolith der Tharandter-Wald-Caldera. Äolische Sedimente sind aus der sächsischen Kreide nicht bekannt.

\section{Schlüsselworte}

Sachsen, Oberkreide, Lithostratigraphie, Sandstein, Skolithos-Ichnofazies, Steinbruch, historischer Werkstein, Geotop

Copyright Birgit Niebuhr et al. This is an open access article distributed under the terms of the Creative Commons Attribution License (CC BY 4.0), which permits unrestricted use, distribution, and reproduction in any medium, provided the original author and source are credited. 


\section{Abstract}

The sandstone quarry at Flügel Jägerhorn, west of Grillenburg is probably being the oldest Cretaceous sandstone quarry of the Tharandter Wald, already commenced operation in 1170. It has been historically proven that in 1225 the Golden Portal of the Freiberg St. Marien Cathedral was built of Grillenburg Sandstone, for example. The copperplate engravings of the bivalve Rastellum carinatum and the pectinid Merklinia aspera from the "sandstone quarry of the Grüllenburger Walde", published by the polymath J.F. Henckel (1722), are the oldest known illustrations of Saxonian Cretaceous fossils in literature.

Within the lowermost part of the sandstone quarry at the Flügel Jägerhorn the more than 5-m-thick "Freestone Bed", the sandy freestone of the marine upper Oberhäslich Formation (lower Upper Cenomanian) is exposed, erroneously assigned to the continental Niederschöna Formation (Lower Cenomanian) for more than 130 years and interpreted as a fossil-free aeolian sandstone. In addition to glauconite, the uppermost 1.50-2 m of the "Freestone Bed" also contains five different trace fossils of the Skolithos Ichnofacies which characterizes sandy, shallow-marine environments. It is overlain by the Pennrich Formation (upper Upper Cenomanian) that starts with the ca. 1.50-m-thick plenus Horizon and a basal transgression conglomerate yielding well-rounded rhyolite cobbles of up to $15 \mathrm{~cm}$. At the top of the outcrop, 3-7-m-thick well-bedded, spiculitic-glauconitic siltstones are preserved.

This lithostratigraphic sequence is typical for the Osterzgebirge: marine Middle and Upper Cenomanian are superimposed on continental Lower Cenomanian. The middle and upper Oberhäslich Formation of the Tharandter Wald - above the fluvial middle Niederschöna Formation and overlain by the deeper-marine Pennrich Formation - is about $20 \mathrm{~m}$ thick; however, just the topmost 5-7 $\mathrm{m}$ have been quarried as the only Cenomanian sandy freestone of the Saxonian Cretaceous. Near Grillenburg, strata of the Oberhäslich and Pennrich formations also directly transgress onto the Permian rhyolite of the Tharandter Wald Caldera. Aeolic sediments are unknown from the Saxonian Cretaceous.

\section{Keywords}

Saxony, Upper Cretaceous, lithostratigraphy, sandstone, Skolithos Ichnofacies, quarry, historical freestone, geotope

\section{Meeresspiegelanstieg während des Cenomaniums in der sächsischen Kreide}

Die Elbtalkreide des Sächsischen Kreidebeckens wurde in einer Nordwest-Südost-verlaufenden, recht engen Meeresstraße zwischen der großen Mitteleuropäischen Insel im Südwesten und der kleinen Westsudetischen Insel im Nordosten abgelagert. Im Nordwesten bestand eine Verbindung zum breiten, offen-marinen und kühl-temperierten borealen Schelfmeer, nach Südosten öffnet sich auf tschechischer Seite das wesentlich größere Böhmische Kreidebecken mit seiner Verbindung zum warmen Tethys-Meer. Erosionsrelikte dieser Ablagerungen, die lithostratigraphisch in der Elbtal-Gruppe zusammengefasst werden (Niebuhr et al. 2007), finden sich auch auf dem Osterzgebirge von Dresden bis über Freiberg hinaus. Zwischen dem Tharandter Wald und der Dippoldiswalder Heide lässt sich der fortschreitende globale Meeresspiegelanstieg während des Cenomaniums exemplarisch nachvollziehen (Abb. 1, 2a).

Ein erster Meeresvorstoß von Norden erfolgte im späten Untercenomanium vor etwa 97 Millionen Jahren (Ma) und erreichte das heutige Niederau nordöstlich von Meißen; dort wurde der flachmarine Klippensandstein der unteren Oberhäslich-Formation abgelagert (Wilmsen et al. 2019; Wilmsen und Bansal 2021; Niebuhr und Wilmsen, in Vorber.). Währenddessen beginnt der „Niederschönaer Fluss", der als weit verzweigtes Flusssystem das Osterzgebirge nach Norden bis Nordosten entwässerte, erst Konglomerate und Brekzien mit sandig-kaolinitischer
Grundmasse (Grundschotter, untere Niederschöna-Formation), später graue, unreife Rinnensande und pflanzenführende, tonige Auensedimente („Crednerienschichten“, mittlere Niederschöna-Formation) in seinen Flussbetten abzulagern (Krutzsch 1966; Voigt 1998; Niebuhr und Wilmsen, in Vorber.; siehe Abb. 1: „Untercenomanium“).

Der zweite Meeresvorstoß im Mittelcenomanium vor etwa 96 Ma führte im Nordwesten zu den marinen Ablagerungen der tonig-mergeligen Mobschatz-Formation und des Roten Konglomerats der Meißen-Formation (Wilmsen et al. 2019). Graue, unreife Sandsteine mit kohligen Tonlagen, marinen Spurenfossilien und Glaukonit, die in den Mündungsbereichen des Niederschönaer Flusssystems abgelagert wurden (brackischer Wurmsandstein, obere Niederschöna-Formation), sind in Bohrungen von Pirna bis in die Sächsische Schweiz nachzuweisen (Janetschke und Wilmsen 2014; Wilmsen und Bansal 2021; Niebuhr und Wilmsen, in Vorber.). Das Osterzgebirge zwischen Tharandter Wald bis hinunter nach Dippoldiswalde wird erstmals in der Kreide zum marinen Ablagerungsraum (Wilmsen et al. 2022; Niebuhr und Wilmsen, in Vorber.). Zu Beginn der Transgression wurden die Flusstäler des ehemaligen „Niederschönaer Flusses" geflutet (cf. Voigt 1998), später auch vormals festländische, paläozoische Gesteine (siehe Abb. 1: „Mittelcenomanium"). So liegt bei Grillenburg die mittlere Oberhäslich-Formation sowohl auf der fluviatilen, mittleren Niederschöna-Formation als auch direkt auf dem permischen Rhyolith der Tharandter-Wald-Caldera, der eine hauptsächlich NNE-SSW-verlaufende Insel zwischen Grillenburg und Pohrsdorf bildete (Tröger 1969: S. 22, Anl. 4, 13; Niebuhr et al., siehe unten Abb. 4). 


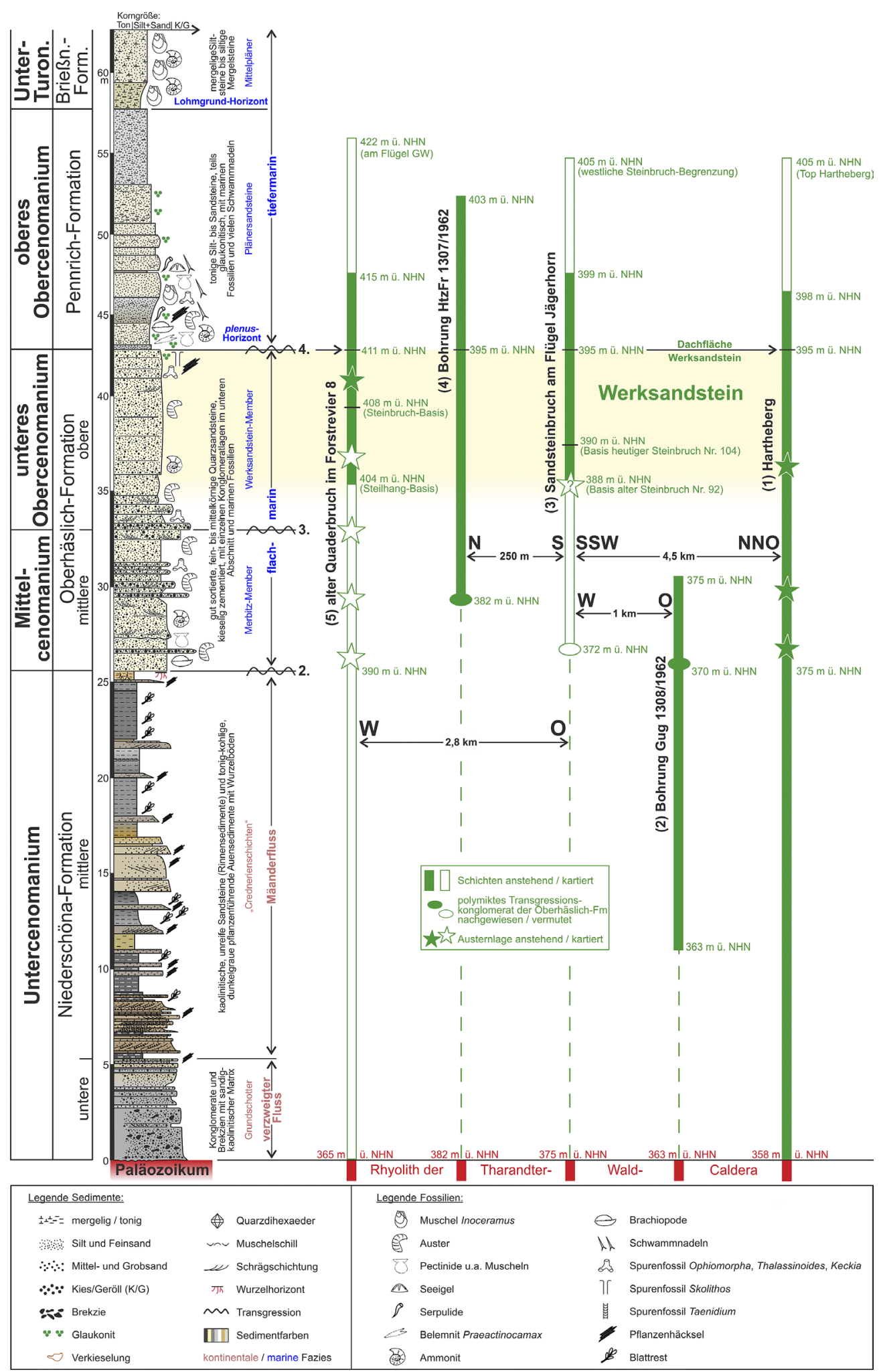

Abbildung 1. Zusammengesetztes geologisches Standardprofil des Cenomaniums auf dem Osterzgebirge mit stratigraphischer Reichweite der hier bearbeiteten Profile (grün). Die Niederschöna-Formation basiert auf der Bohrung Oelsa B7/1991 (Voigt 1998; Profilaufnahme M. Wilmsen 06/2021), die Oberhäslich-Formation auf dem Profil am Sandberg in der Paulsdorfer Heide und die Pennrich- sowie Brießnitz-Formation auf dem Profil am Horkenberg bei Bannewitz (beide Profile aus Janetschke und Wilmsen 2014). Unterturon. $=$ Unterturonium; Brießn.-Form. $=$ Brießnitz-Formation. Die Fossilien charakterisieren verschiedene Profile auf dem Osterzgebirge.

Figure 1. Composed geological standard section of the Cenomanian of the Osterzgebirge with the stratigraphic range of the sections measured herein (green). The Niederschöna Formation is based on the borehole Oelsa B7/1991 (Voigt 1998; core logging M. Wilmsen 06/2021), the Oberhäslich Formation of the Sandberg section in the Paulsdorfer Heide and the Pennrich as well as Brießnitz Formation of the Horkenberg section near Bannewitz (sections from Janetschke and Wilmsen 2014). Unterturon. = Lower Turonian; Brießn.-Form. = Brießnitz Formation. The fossils characterize different sections of the Osterzgebirge. 
Der dritte Meeresvorstoß im frühen Obercenomanium vor etwa $95 \mathrm{Ma}$ flutete auch die restlichen Areale des Sächsischen Kreidebeckens einschließlich der Verbindung zum Böhmischen Kreidebecken. Der Werksandstein der oberen Oberhäslich-Formation, ein massiger, hell-gelblicher, gut sortierter und reiner Quarzsandstein ohne Tonlagen, wurde lithologisch relativ einheitlich über einem ausgeprägten Paläorelief von Senken und Schwellen abgelagert und ist im Untergrund von Dresden über Pirna bis in die Sächsische Schweiz zu finden (Janetschke und Wilmsen 2014; Janetschke et al. 2015; Wilmsen 2017; Wilmsen und Bansal 2021; siehe Abb. 1: ,unteres Obercenomanium“). Auf dem Osterzgebirge wurde er als einziger cenomanzeitlicher Werksandstein in zahlreichen Steinbrüchen abgebaut, so auch in Grillenburg (Niebuhr et al., siehe unten Abb. 11).

Die vierte Transgression im oberen Obercenomanium vor etwa 94,5 Ma erfolgte sehr rasch und führte zum Ertrinken vieler ehemaliger Inseln und auch zum direkten Auflager der sandigen Pennrich-Formation und der zeitgleichen, mergeligen Dölzschen-Formation auf vormals festländische, paläozoische Gesteine (Voigt et al. 1994; Voigt et al. 2006; Wilmsen et al. 2011; Janetschke und Wilmsen 2014; Janetschke et al. 2015; Wilmsen und Bansal 2021). Bei Grillenburg liegt die Pennrich-Formation (mit dem markanten Rhyolith-Konglomerat) nicht nur auf dem Werksandstein der oberen Oberhäslich-Formation, sondern transgrediert westlich vom Sandsteinbruch am Flügel Jägerhorn ebenfalls direkt auf den Rhyolith (Tröger 1969: S. 27, Anl. 6, 14; Niebuhr et al., siehe unten Abb. 4). Die Küstenlinie wurde mit dieser Transgression weit nach Westen auf das Erzgebirge verschoben, sodass die Umgebung von Grillenburg nur noch von feinkörnigem Silt und Ton erreicht wurde (Niebuhr et al., siehe unten Abb. 11). Der globale Meeresspiegelanstieg während des Cenomaniums hat im Sächsischen Kreidebecken das Meer in nur etwa 3 Millionen Jahren (etwa 97-94 Ma) um bis zu $70 \mathrm{~m}$ ansteigen lassen (M. Wilmsen, mündl. Mitt. 02/2021). Im unteren Unterturonium wurden im Lohmgrund-Horizont der Brießnitz-Formation vermutlich die größten Wassertiefen in der Elbtalkreide erreicht (Niebuhr et al. 2020; Wilmsen und Bansal 2021; siehe Abb. 1: „,unteres Unterturonium“").

\section{Kreidesandstein-Lokalitäten}

Der Tharandter Wald liegt fast zur Gänze auf den nördlichen Hälften der geologischen Kartenblätter 80/5046 Freiberg und 81 Tharandt / 5047 Freital (Abb. 2b). Beide Blätter wurden unter der Leitung von Hermann Credner in der Kartierkampagne Ende des 19. Jahrhunderts erstmalig aufgenommen (Sauer 1886, 1887, 1889, 1891; Kartenausschnitt der ersten GK 25: 80 Freiberg um den Sandsteinbruch am Flügel Jägerhorn siehe Abb. 3). In der zeitnah folgenden 2. Auflage differenziert Sauer (1899, 1900) auf Blatt 80 Freiberg die Kreidesandsteine in ,c1s“ (,Zone der Crednerien“ und „Carinatenquader“ / Nieder- schöna- und Oberhäslich-Formation) und „,clps“ (,glaukonitischer Plänersandstein" / mittlere und obere Pennrich-Formation) sowie Pietzsch $(1912,1914)$ auf Blatt 81 Tharandt in „c1k+c1t+c1c“ (,Fluviatil-limnisches Cenoman: Stufe der Crednerien“ / Niederschöna-Formation), „c1s“" (,Carinatenquader" / Oberhäslich-Formation) und „c2s“ („Plänersandstein mit Cidaris Sorigneti“ / mittlere und obere Pennrich-Formation). Die Oberhäslich-/ Pennrich-Formationsgrenze war bereits in der 1. und 2 . Auflage der beiden Kartenblätter als Carinatenquader-/ Plänersandstein-Grenze verzeichnet, allerdings wurde der 1-2 m dünne plenus-Horizont (als „Serpulasande“, später auch „Pennricher Sandstein“) dem obersten Carinatenquader zugerechnet (Sauer 1899; Pietzsch 1912) und nicht, wie heute, der basalen Pennrich-Formation (vgl. Niebuhr 2020).

Die Grenzziehungen zwischen der marinen Oberhäslich-Formation im Hangenden und der fluviatilen Niederschöna-Formation im Liegenden wurde mit den sogenannten „Exogyrenbänken im unteren Quadersandstein“ gezogen, die charakteristisch für die mittlere Oberhäslich-Formation und ebenfalls bereits in der 1. Auflage der Kartenblätter eingezeichnet sind (Sauer 1886, 1889). Da sich die Definition der lithostratigraphischen Einheiten im Laufe der Zeit nur wenig geändert hat, lassen sich die Grenzen der heutigen drei cenomanzeitlichen Formationen auf dem Osterzgebirge aus den alten Karten mit einer Genauigkeit von $\pm 2 \mathrm{~m}$ noch recht präzise herleiten.

Grillenburg liegt im Zentrum des Tharandter Waldes, die Kartenblattgrenze 80/5046 Freiberg zu 81 Tharandt / 5047 Freital durchschneidet in Nord-Süd-Richtung den Zugangsweg zum Sandsteinbruch am Flügel Jägerhorn (Abb. 2b, 4a). Als lithologisches Alleinstellungsmerkmal dieses Steinbruchs gilt das Rhyolith-Konglomerat, das etwa im mittleren Bereich der ca. $10 \mathrm{~m}$ hohen Wand der sogenannten „Werksteinbank“ aufliegt. Um die lithologische Entwicklung bei Grillenburg mit der anderer Kreidesandstein-Lokalitäten vergleichen zu können, wurden (neben vier Bohrungen in unmittelbarer Umgebung) zwei bekannte Sandsteinbrüche (Hartheberg, ca. 4,5 km im Nordnordosten; alter Quaderbruch im Forstrevier 8, ca. 2,8 km im Westen; Abb. 1, 2b) zur Korrelation herangezogen. In allen drei Steinbrüchen liegen cenomanzeitliche Kreidesandsteine dem permischen Rhyolith der Tharandter-Wald-Caldera auf.

(1) Hartheberg - TK 25: 5047 Freital; (1a) 33U: E 397224 / N 5649271 (Nr. 119 bei Eberlein 2004), Nord-Hang des Harthebergs, rechts der Straße K 9072 vom Kurort Hartha nach Spechtshausen, Basis des Steinbruchs $375 \mathrm{~m}$ ü. NHN, mittlere Oberhäslich-Formation mit basaler, 30-50 cm mächtiger „Exogyrenbank“ zwischen 375-380 m ü. NHN, auflagernd auf der fluviatilen, mittleren Niederschöna-Formation (Sauer 1891: S. 72; Pietzsch 1912; Schreiter 1927: S. 94); (1b) 33U: E 397423 / N 5648851 (Nr. 57 bei Tröger 1969; Nr. 121 bei Eberlein 2004), Südost-Hang des Harthebergs westlich vom Kurort Hartha, ehemalige Basis des Steinbruchs 375 m ü. NHN mit basaler „Exogyrenbank“ bei $380 \mathrm{~m}$ 


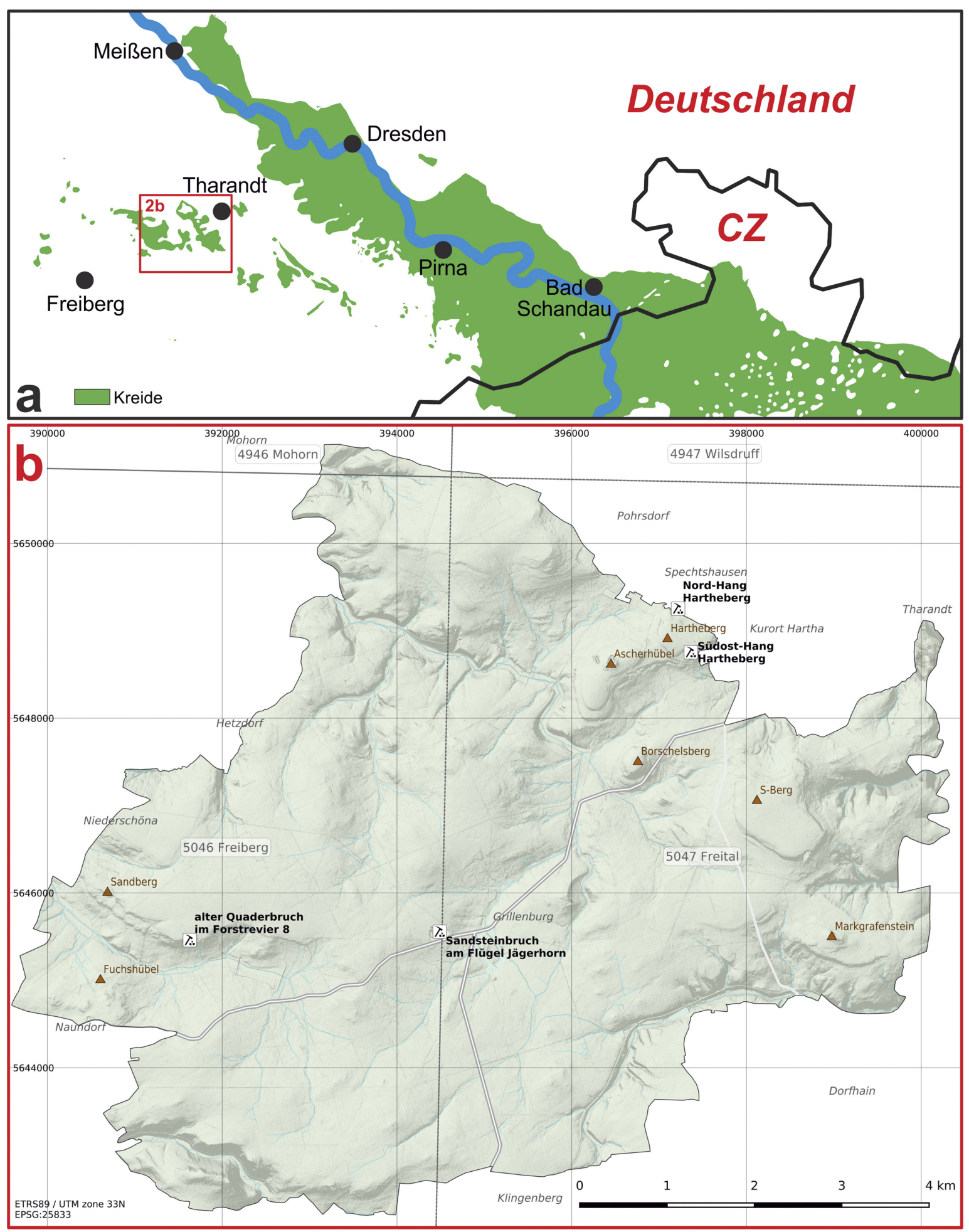

Abbildung 2. a Das Sächsische und nördliche Böhmische Kreidebecken in Deutschland und Tschechien (B. Niebuhr 02/2021, nach M. Fengler, www.kreidefossilien.de/1882) mit Lage des Arbeitsgebietes. b Digitales Höhenmodell (DGM; GeoSN 2021) des Tharandter Waldes mit den bearbeiteten Sandsteinbrüchen und den Erhebungen, die maßgeblich von Kreidesandsteinen aufgebaut werden.

Figure 2. a The Saxonian and northern Bohemian Cretaceous basins in Germany and Czechia (B. Niebuhr 02/2021, according to M. Fengler, www.kreidefossilien.de/1882) including the position of the study area. b Digital elevation model (DEM; GeoSN 2021) of the Tharandter Wald showing the studied sandstone quarries and elevations mainly formed by Cretaceous sandstones.

ü. NHN und höher (Schreiter 1927: S. 93, 94) und einer weiteren „Exogyrenbank“ bei ca. 389 m ü. NHN (Tröger 1969: Anl. 4), Dachfläche des Werksandsteins der oberen Oberhäslich-Formation ca. 395 m ü. NHN, im Hangen- den heute noch ca. 2 m plenus-Horizont (,locker-sandige Schichten“, Häntzschel 1933: S. 17) und 1 m Plänersandsteine der Pennrich-Formation im Steinbruch anstehend (siehe Profil bei Martick 1999; Eberlein 2004: Abb. 5.49). 
Die Plänersandsteine wurden (als sandige Dölzschen-Formation) bis auf den Gipfel des Harthebergs bei 405,50 m ü. NHN nachgewiesen (Alexowsky et al. 2012).

(2) Wismut-Bohrung Gug 1308/1962 - TK 25: 5047 Freital, 33U: E 395359 / N 5645849, nordöstlicher Ortsausgang Grillenburg, am Zentralparkplatz, Hauptstraße S 194 (Abb. 4); Bohransatz 377 m ü. NHN, Top Kreideschichten 375 m ü. NHN, Basis Kreideschichten auf verwittertem Rhyolith $363 \mathrm{~m}$ ü. NHN (Tröger in Alexowsky et al. 2012: S. 170).

Die Bohrung Gug 1308/1962 wurde erstmalig von der Wismut aufgenommen und später von Tröger (in Alexowsky et al. 2012) interpretiert. Sie durchteuft unter einer dünnen Lehmschicht (Quartär) mittel- bis grobkörnige Quarzsandsteine der mittleren Oberhäslich-Formation. Diese sind kieselig-limonitisch zementiert und weisen an der Basis ein $20 \mathrm{~cm}$ dünnes, polymiktes Transgressionskonglomerat auf (2,40-6,60 m Teufe / 375-370 m ü. NHN). Die fluviatile, mittlere Niederschöna-Formation (6,60-14,50 m Teufe / 370-363 m ü. NHN) besteht aus tonigen, gelbgrauen Sandsteinen, denen vereinzelte, dünne Konglomeratbänke zwischengeschaltet sind. An der Basis liegen grobe Quarzkonglomerate mit Geröllen bis $20 \mathrm{~mm}$. Der Rhyolith, dem die Kreideschichten bei 14,50 m Teufe / $363 \mathrm{~m}$ ü. NHN aufliegen, weist eine 5-6 $\mathrm{m}$ tiefgreifende prä-cenomane Rotlehmverwitterung auf.

Der ca. 300 m südwestlich der Bohrung Gug 1308/1962 gelegene Brunnen der ehemaligen Grillenburger Schule (Abb. 4) erreichte ,in etwa $4 \mathrm{~m}$ Tiefe [ca. $370 \mathrm{~m}$ ü. NHN] glimmerige, dünnschieferige, auf ihren Schichtfächen reichlichst mit verkohlten Pfanzenresten bedeckte Sandsteine, welche vollkommen mit den kohligen Sandsteinen von Niederschöna übereinstimmen" (Sauer 1891: S. 69). Nach heutiger Klassifikation handelt es sich dabei um Ablagerungen der fluviatilen, mittleren NiederschönaFormation.

(3) Grillenburger Sandsteinbruch am Flügel Jägerhorn - TK 25: 5046 Freiberg, 33U: E 394416 / N 5645611 (Nr. 56 bei Tröger 1969; Nr. 104 bei Eberlein 2004), westlicher Ortsausgang Grillenburg, ,im Buchstaben W“ = W-Flügel (Sternflügel) zwischen den Schneisen 15 und 16, heutiger Eingang des Steinbruchs Nr. 104 Flügel Jägerhorn, ca. $50 \mathrm{~m}$ links nach dem Abzweig von der Straße S194 in Richtung Freiberg (Abb. 4a); Basis des Steinbruchs 390 m ü. NHN, Dachfläche des Werksandsteins der oberen Oberhäslich-Formation im hinteren, westlichen Abschnitt 395 m ü. NHN, leicht einfallend nach Südosten, darüber noch wenige Meter der Pennrich-Formation anstehend. Am östlichen Ausgang des Steinbruchs wurde der Werksandstein (als , $\mathrm{s}_{\mathrm{f}} \mathrm{Kc}^{1-2} \mathrm{Nis}$, Flussablagerungen, Niederschöna-Formation, Unter- bis Mittelcenoman“, Alexowsky et al. 2012) bis auf 372 m ü. NHN herunter kartiert, auflagernd auf dem Rhyolith der Tharandter-Wald-Caldera.

Solange der Sandsteinbruch in Betrieb war, erfolgte der Zugang von der Straße S 194 in Richtung Freiberg aus, des ehemaligen D-Flügels, ca. $200 \mathrm{~m}$ westlich des Abzweigs in den Flügel Jägerhorn (Sauer 1886; Schrei-

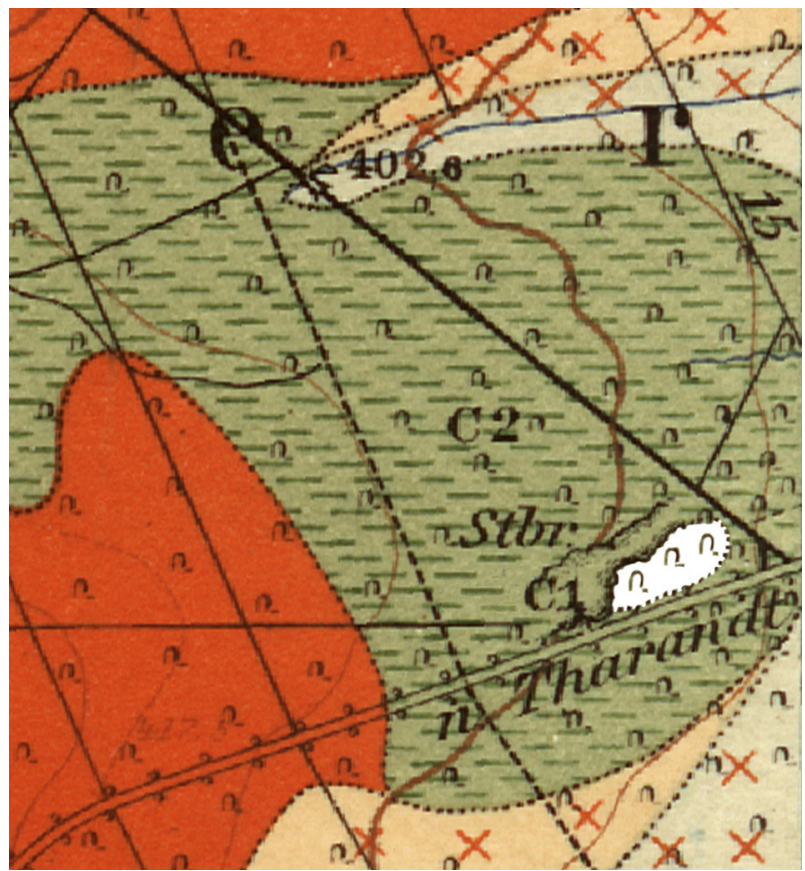

Abildung 3. Ausschnitt aus der ersten GK 25: 80 Freiberg um den Sandsteinbruch am Flügel Jägerhorn (Sauer 1886). Beachte den südlichen Zugang von der Straße S 194 Freiberg-Tharandt / D-Flügel. Legende: rot - „Quarzporphyr“; grün „c1, c2““-,Unterer Quadersandstein, Unterer glaukonitischer Plänersandstein“; weiß - Halde.

Figure 3. Detail of the first geological map GK 25: 80 Freiberg in the vicinity of the sandstone quarry at the Flügel Jägerhorn (Sauer 1886); note the southern entrance from road S 194 Freiberg-Tharandt / D-Flügel. Red - "quartzose porphyry"; green "c1, c2" - "Lower Quader sandstone, Lower glauconitic Pläner sandstone"; white - heap.

ter 1927: S. 78; Abb. 3, 15). Im dahinter liegenden alten Steinbruch Nr. 92 (33U: E 394424 / N 5645540; Nr. 92 bei Eberlein 2004; Abb. 3, 4a) reichte das Kreidesandstein-Profil noch ca. 1,60 m tiefer als im heutigen Steinbruch Nr. 104 (Göhler 2006a). Am westlichen Rand des Steinbruch-Gebiets steht das dort $80 \mathrm{~cm}$ mächtige, kompakte Rhyolith-Konglomerat flächig an (schwarze Punkte an der Basis der Pennrich-Formation, Abb. 4a).

(4) Wismut-Bohrung HtzFr 1307/1962 - TK 25: 5046 Freiberg, 33U: E 394315 / N 5645810, am Flügel Jägerhorn, $210 \mathrm{~m}$ nördlich des Sandsteinbruchs (Abb. 4); Bohransatz 405 m ü. NHN, Top Kreideschichten 403 m ü. NHN, Dachfläche des Werksandsteins der oberen Oberhäslich-Formation $394 \mathrm{~m}$ ü. NHN, Basis Kreideschichten auf Rhyolith $382 \mathrm{~m}$ ü. NHN.

Die Bohrung HtzFr 1307/1962 wurde erstmalig von der Wismut aufgenommen und hier neu interpretiert. Sie durchteuft unter einer dünnen Lehmschicht (Quartär) gelbbraune, feinkörnige und schwach tonige Plänersandsteine, die durch Limonit zementiert sind, und darunter den $1,80 \mathrm{~m}$ mächtigen, graugelblichen, tonigen plenusHorizont der Pennrich-Formation (2,20-11 m Teufe / 403-394 m ü. NHN). Von 11-23,20 m Teufe / 394-382 m ü. NHN treten graue Fein- bis Mittelsandsteine auf, die an 

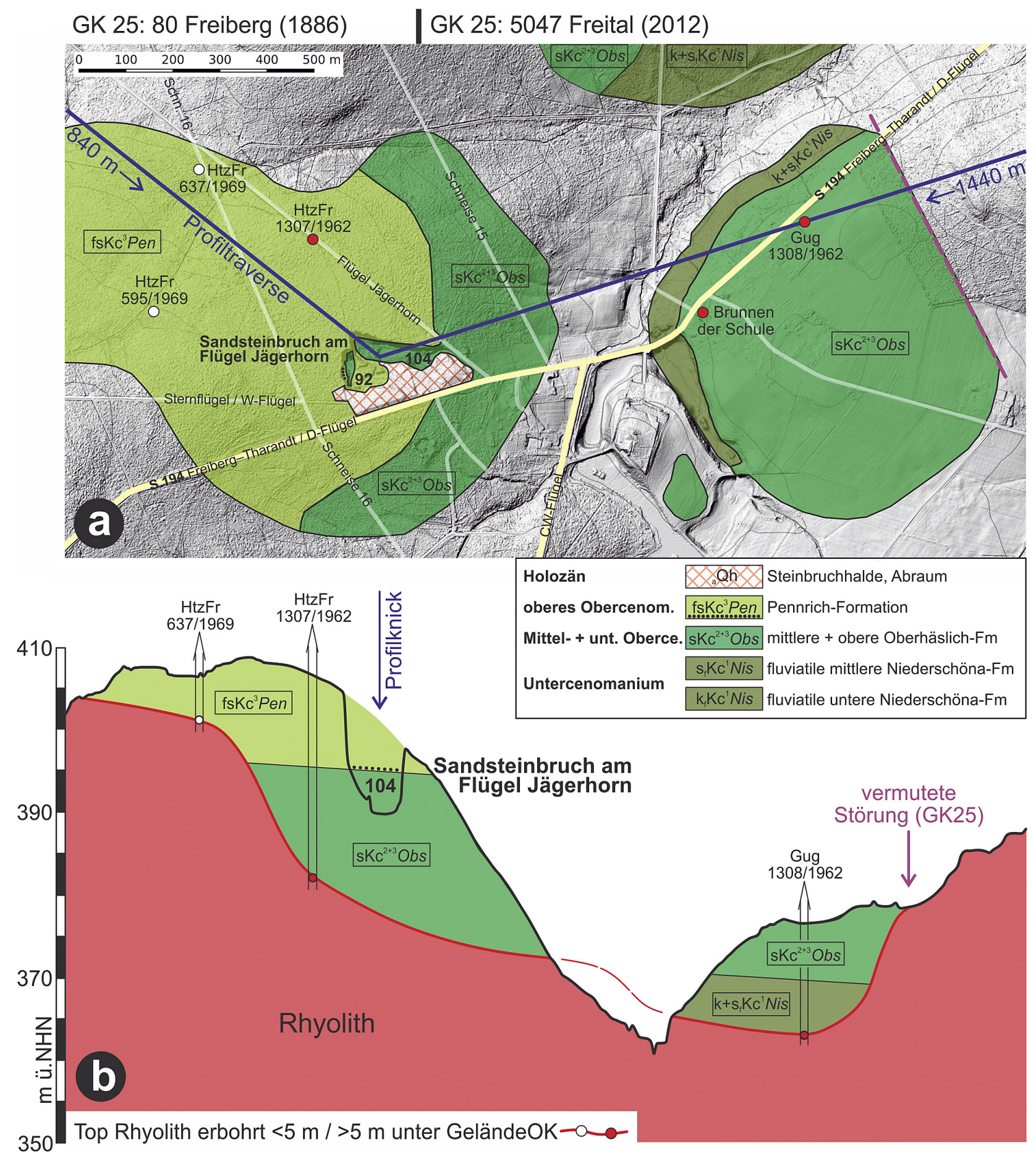

Abbildung 4. a Digitales Geländemodell (DGM; GeoSN 2021) mit Ausschnitt aus der GK 25: 80 Freiberg (Sauer 1886) und 5047 Freital (Alexowsky et al. 2012) bei Grillenburg. Beachte geänderten Ausbiss (unter dünner Quartär-Bedeckung) und Vorschlag einer modifizierten stratigraphischen Gliederung der cenomanzeitlichen Sedimente gemäß Abb. 1. b Geologischer Schnitt der Kreidesandsteine auf dem Rhyolith der Tharandter-Wald-Caldera zwischen 350-410 m ü. NHN, stark überhöht.

Figure 4. a Digital elevation model (DEM; GeoSN 2021) with detail of the GK 25: 80 Freiberg (Sauer 1886) and 5047 Freital (Alexowsky et al. 2012) near Grillenburg. Note changed exposure (below thin Quaternary cover) and the proposal of a modified stratigraphic subdivision of the Cenomanian sandstones according to Fig. 1. b Geological cross-section of the Cretaceous sandstones overlying the rhyolite of the Tharandter Wald Caldera at heights of 350-410 m a.s.l., strongly vertically exaggerated.

der Basis ein 4 m mächtiges, polymiktes Transgressionskonglomerat mit Rhyolith-Geröllen aufweisen (mittlere und obere Oberhäslich-Formation). Die Kreidesandsteine liegen bei $382 \mathrm{~m}$ ü. NHN direkt dem Rhyolith auf.
In zwei weiteren Wismut-Bohrungen, nur ca. $500 \mathrm{~m}$ vom Sandsteinbruch entfernt (TK 25: 5046 Freiberg; HtzFr 637/1969, 33U: E 394073 / N 5645957 und HtzFr 595/1969, 33U: E 393977 / N 5645658), wurde der 
Rhyolith unter der Überdeckung durch 1-2 m Quartär und 3-4 m Plänersandsteinen der Pennrich-Formation auf $401 \mathrm{~m}$ resp. $410 \mathrm{~m}$ ü. NHN erbohrt (Abb. 4).

(5) Alter Quaderbruch im Forstrevier 8 - TK 25: 5046 Freiberg, 33U: E 391629 / N 5645466 (Nr. 55 bei Tröger 1969; Nr. 108 bei Eberlein 2004), ,am südlichen Gehänge des GW-Flügels, Abtl. 8 des Nauendorfer Revieres“ Zwischen den Schneisen 21 und 22, ca. 2 km südöstlich vom Forsthaus Niederschöna (Sauer 1886, 1887: S. 43; Horn 1938: S. 51).

In dem alten Quaderbruch wurden die obersten $3 \mathrm{~m}$ (ca. 408-411 m ü. NHN) der Oberhäslich-Formation gebrochen. Die wellige Dachfläche zeigt Gangquerschnitte mariner Spurenfossilien (Göhler 2011). In dem stark eisenschüssigen Werksandstein fand Sauer (1887: S. 43) „eine vollständige Austernbank mit Tausenden von Exogyren von $3 \mathrm{~cm}$ Grösse bis zur kleinsten Brut." Einem großmaßstäblichen Abbau stand der heute noch steile Zugang über eine mehrere Meter hohe Geländekante im Liegenden des Steinbruchgebietes im Wege, die vom Werksandstein mit „Exogyrenbänken“ gebildet wird („Dünensandstein“ bei Göhler 2011). Oberhalb von ca. $411 \mathrm{~m}$ ü. NHN schließt im Steinbruch die Pennrich-Formation mit dem fossilreichen, feinkörnigen und kaum verfestigten plenus-Horizont an (,Serpulasande“ bei Horn 1938) und reicht mit Plänersandsteinen bis auf ca. 422 m ü. NHN hinauf (Sauer 1899).

\section{Leithorizont}

Der Horizont, mit dem die Kreidesandsteinprofile des Osterzgebirges korreliert werden können, ist die Dachfläche des Werksandsteins (Sequenzgrenze SB Ce 5; Janetschke und Wilmsen 2014; Janetschke et al. 2015), der in allen Abbauten der Steinbruch-Betrieb folgte (Abb. 1; Hartheberg: 395 m ü. NHN - Sandsteinbruch am Flügel Jägerhorn: $395 \mathrm{~m}$ ü. NHN - alter Quaderbruch: $411 \mathrm{~m}$ ü. NHN). Auf der ca. $150 \mathrm{~m}$ lange Ost-West-Erstreckung des anstehenden Werksandsteins im heutigen Steinbruch Nr. 104 und der ca. 60 m langen Nord-Süd-Erstreckung im alten Steinbruch Nr. 92 ist zu erkennen, dass die Dachfläche des Werksandsteins am Flügel Jägerhorn ein deutliches Einfallen nach Südosten aufweist. Die Höhenlage des Werksandsteins im 2,8 km westlich von Grillenburg liegenden alten Quaderbruch deutet auf einen post-kretazischen Versatz des Osterzgebirges von ca. $16 \mathrm{~m}$ hin (411 versus $395 \mathrm{~m}$ ü. NHN). Nach diesem Einfallen, in Richtung Südosten verlängert, müsste die Dachfläche des Werksandsteins in der Bohrung Gug 1308/1962 ca. $1 \mathrm{~km}$ östlich am Ortsausgang von Grillenburg (Oberhäslich-Formation bei Tröger in Alexowsky et al. 2012: S. 170) etwa auf $392 \mathrm{~m}$ ü. NHN liegen. So ergibt sich eine Mächtigkeit der mittleren und oberen Oberhäslich-Formation bei Grillenburg (Mittel- und unteres Obercenomanium nach Wilmsen et al. 2022) - auflagernd auf der fluviatilen, mittleren Niederschöna-Formation (Untercenomanium) und überlagert von der Pennrich-Formation (unteres Obercenomanium) - von etwa $22 \mathrm{~m}$.

\section{Historie}

Der Grillenburger Sandsteinbruch ist Zeugnis einer über Jahrhunderte andauernden Abbautätigkeit nach Werksandsteinen im Tharandter Wald (Bachmann 1936; Grunert 1986; Siedel et al. 2011). Die Quellenlage zum Werdegang dieses Steinbruches scheint sehr lückenhaft zu sein. Eine Beschriftung „stein-bruch“ unmittelbar westlich von „Grülleburgk“ an dem mit „B“ bezeichneten Weg findet sich auf einer Karte der ersten Landesvermessung des Kurstaates Sachsen von 1588 (Oeder in Ruge 1889). Dieser „Bau-Weg nach Grüllenburg“ (dem Grillenburger Schloss, Fleischer 1963: S. 223) ist die Straße im Herzen des Tharandter Waldes von Freiberg über Naundorf, Grillenburg und Hartha nach Tharandt, die heutige S 194 bzw. der D-Flügel der alten geologischen Karten (Sauer 1886, 1889, 1899; Pietzsch 1912).

Die Herkunft zahlreicher bedeutender Bauten und Skulpturen aus dem Sandstein des „Grillenburger Waldes“" wird in diesem Steinbruch verortet (Herrmann 1899, 1916) - auch aufgrund petrographisch-gesteinstechnischer Untersuchungen (Prescher 1957; Beeger et al. 1962; Grunert 1986; Götze und Siedel 2004; Siedel et al. 2011). Aus dem Sandsteinbruch am Flügel Jägerhorn wurde ab etwa 1170 zum ,schnellen Aufbau Freibergs zur damals größten Stadt Sachsens das prachtvolle Sandsteinmaterial [...] zum Bau großer Kirchen, des neuen markgräflichen Schlosses und nicht zuletzt der berühmten Goldenen Pforte in Freiberg“" gebrochen (Bachmann 1936); ab 1216 diente der Grillenburger Werksandstein beim Bau des Jagdsitzes auch in Grillenburg selbst (Colmnitzer Tor im Südwesten; Beeger und Siedel 2007: S. 40). Die Goldene Pforte des Freiberger St.-Marien-Doms (Abb. 5) und das an der Westseite der Stadtkirche in Nossen befindlichen Portal, das ursprünglich am Kloster Altzella verbaut war, entstanden zwischen 1220-1230 (Grunert 1986: S. 111; Beeger und Siedel 2007: S. 40; Siedel et al. 2011: S. 190). Noch älter sind Werkstücke des Lapidariums der Klosterkirche Altzella (um 1170; Beeger in Grunert 1986: S. 11; Beeger 1994). Sehr wahrscheinlich wurden auch Figuren und Schmuckelemente im Innenraum des Meißner Doms (erbaut 1266-1290) und des Freiberger Doms (nach 1484) aus dem Material gefertigt, das unter der Bezeichnung „Grillenburger Sandstein“ bekannt ist (Beeger 1994; Götze und Siedel 2004; Beeger und Siedel 2007: S. 40; Siedel et al. 2011: S. 208). Natürlich wurde auch in die auf älteren Grundmauern errichtete kurfürstliche Jagdhausanlage in Grillenburg (,Gryllenburg“, „Grüllenburg“, „Grillenburgk“), großenteils entstanden 1554-1558, Sandstein vom Flügel Jägerhorn verbaut. Nach einer etwa 140 Jahre währenden Unterbrechung der Abbautätigkeit wurde etwa 1730 wieder der „Quadersandstein“ aus dem kurfürstlichen Steinbruch bei Grillenburg im Tharandter Wald gewonnen, aus dem 1585-1588 (zur Zeit der ersten sächsischen Landesvermessung, siehe oben) auch ,schon das neuere Frauensteiner Schloß [...] gebaut worden seyn soll“" (Schiffner 1840: S. 689). 


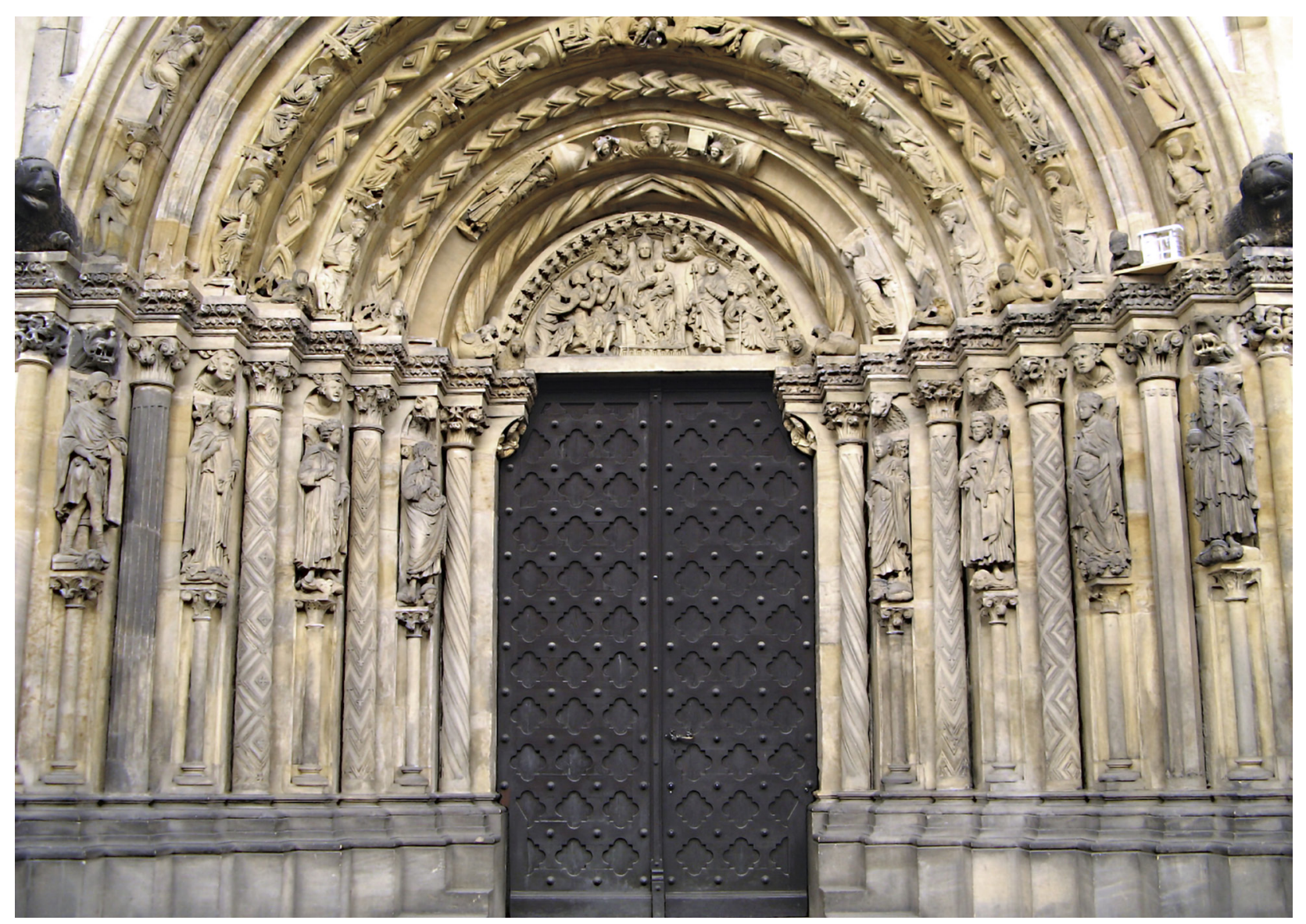

Abbildung 5. Die Goldene Pforte des Freiberger St.-Marien-Doms, erbaut 1225 aus dem Grillenburger Sandstein vom Flügel Jägerhorn (Foto: J. Czoßek 2020).

Figure 5. The Golden Portal of the Freiberg St. Marien Cathedral, built of Grillenburg Sandstone of the Flügel Jägerhorn in 1225 (photo: J. Czoßek 2020).

Auch für die sächsische Kreide-Paläontologie ist der Sandsteinbruch am Flügel Jägerhorn von Bedeutung. In Henckel (1722), „Flora Saturnizans, die Verwandschaft des Pflanzen mit dem Mineral-Reich“, wurden die ältesten bisher bekannten Abbildungen von Fossilien aus der sächsischen Kreide veröffentlicht - gefunden im ,SandStein-Bruche im Grüllenburger Walde“ (Henckel 1722: S. 561): „Hierbei kann ich nicht umhin, dem Liebhaber nebst einem pectine aurio einen sonderbar figurierten Sandstein zu seiner Belustigung und Betrachtung abzuschildern, wie ich solchen selbst gefunden habe und noch besitze. Fig. 1 ist der pecten, sowegen seiner Vollkommenheit und Schönheit in Naturalien-Kammern nicht viel seines gleichen finden wird. Fig. 2 und 3, davon jenes pars convexa, dieses concava ist, scheinet einem Kaulbarsch zu gleichen, ist es aber nicht [...]. Inzwischen ist zu vermuthen, daß es eine Art eines insecti marini sei. Es findet sich diese Figur in einem Sand-Stein-Bruche im Grüllenburger Walde unweit hier sehr häuffig, doch habe ich unter vielen hunderten, eine so ganze Gestalt, als diese ist, nicht zusammen bringen können; darneben sind so eine unzehlige Menge von Muschel- und Schnecken-Werck von sehr vielerlen Sorten, daß es einem Liebhaber nur eine Lust zu sehen ist." Von Henckels Fig. 2 wird Schulze (1769: S. 221), ,auf die Vermuthung geleitet, daß dieselbe von abgerissenen Strahlen einer gewis- sen Art von Seesternen herstammen möge“, seine Fig. 3 zeige ,einen schönen Abdruck von einer ziemlich großen Kammmuschel"“ (Schulze 1769: S. 220).

Das, was Henckel (1722: Fig. 2 und 3) beschrieben und abgebildet hat, sind die beide Seiten derselben linken Klappe einer Hahnenkamm-Muschel Rastellum carinatum (Abb. 7) - sowohl als inneren Steinkern (Abb. 6 links $=$ Henckel 1722: Fig. 2), wie auch als Außenabdruck (Abb. 6 rechts $=$ Henckel 1722: Fig. 3). Zwischen Henckel's beiden Sandsteinhälften befand sich die dicke, jetzt gelöste Kalzitschale. Diese fossile Auster war namensgebend für die frühere lithostratigraphische Bezeichnung „Carinatenquader“ (z. B. Beck 1892, 1889; Petrascheck 1899; Häntzschel 1933), der heutigen mittleren und oberen Oberhäslich-Formation (Mittel- und unteres Obercenomanium nach Wilmsen et al. 2022). Diese Austern sind in allen Kreidesandsteinbrüchen, besonders im unteren Profilabschnitt (mittlere Oberhäslich-Formation) teilweise massenhaft, gefunden worden (Niebuhr et al. 2014; Wilmsen 2017). Henckel (1722: S. 562) beschreibt auch „Muschel-Werck [...] bei Rabenau ohnweit Dippoldiswalde“, von wo auch den Senckenberg Naturhistorischen Sammlungen Dresden, Museum für Mineralogie und Geologie, zahlreiche Exemplare vorliegen (Niebuhr et al. 2014).

Auch der abgebildete Pectinites fabulosus (Henckel 1722: Fig. 1 = Abb. 8 links), der heute Merklinia aspera 


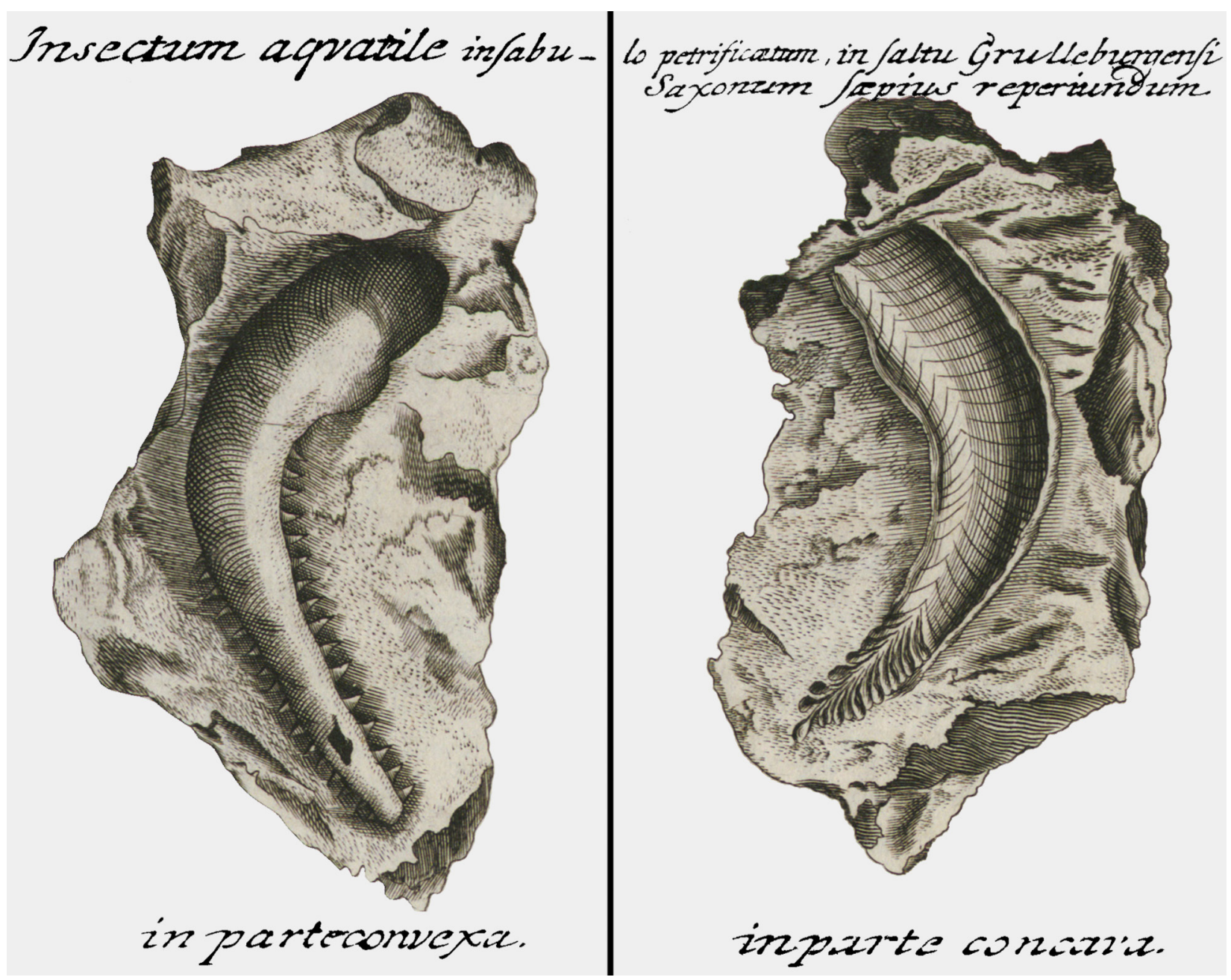

Abbildung 6. Zwei der bisher bekannten drei ältesten Abbildungen von Fossilien aus der sächsischen Kreide zeigen eine linke Klappe der Hahnenkamm-Muschel Rastellum carinatum aus dem Grillenburger Sandstein; Henckel (1722: S. 561 und 562) war der Meinung, dass es „eine Art eines insecti marini sei“. Der linke Steinkern (Henckel 1722: Fig. 2) wird als „,teilweise konvex“ (in parte convexa) und der rechte Außenabdruck (Henckel 1722: Fig. 3) als „,teilweise konkav“ (in parte concava) bezeichnet.

Figure 6. Two of the three oldest images of fossils known from the Saxonian Cretaceous show a left shell of the bivalve Rastellum carinatum from the Grillenburg Sandstone; Henckel (1722: p. 561 and 562) was of the opinion that it is "a kind of insecti marini". The inner imprint at the left side (Henckel 1722: fig. 2) is called "partly convex" (in parte convexa) and the outer imprint at the right side (Henckel 1722: fig. 3) is called "partly concave" (in parte concava).

heißt, ist eine „Leitmuschel“ der Oberhäslich-Formation (Niebuhr et al. 2014). In der sächsischen Kreide ist die Pectinide auf den Zeitabschnitt Mittel- und Obercenomanium beschränkt und sehr häufig, sowohl in mergeliger wie auch sandiger Fazies, zu finden, beispielsweise ebenfalls in der Oberhäslich-Formation von Dippoldiswalde-Oberhäslich (Abb. 8 rechts). Beide namensgebenden Muscheln der ehemaligen „Oberen Stufe des unteren Quadersandsteins mit dem Pecten asper und der Ostrea carinata" (z. B. Sauer 1887: S. 41) sind also seit nunmehr 300 Jahren aus dem Grillenburger Sandstein bekannt.

Der Grillenburger Sandstein wurde Ende des 18. Jahrhunderts zu Skulpturen, Fensterstürzen, Säulen, Trögen und Schleifsteinen verarbeitet (Herrmann 1899; Bachmann 1936). Ab Anfang des 19. Jahrhunderts wurden daraus bevorzugt Schleifsteine für Holzschleifereien gefertigt (Abb. 9), die ,als vorzuglich, selbst in die sandsteinreiche Pirnaer Gegend versendet" wurden und „einen weit über die Grenzen Sachsens hinaus gehenden Ruf" besaßen (Schmidt 1838: S. 176; Sauer 1887: S. 49; Herrmann 1916: S. 243). Ein letzter dieser Grillenburger Schleifsteine (Abb. 9) liegt heute noch vor dem Gebäude der ehemaligen Steinbruchverwaltung in der Seerenteichstraße in Grillenburg. Das Gästehaus Neues Jägerhaus mit seinem in Sandstein gehauenen Eingangsportal hinter dem Jagdschloss Grillenburg, erbaut 1938-1939 (Kantschew 2010), ist vermutlich das letzte Gebäude, für das der Grillenburger Sandstein vom Flügel Jägerhorn noch einmal zum Einsatz kam. Um 1940 wurde der aktive Steinbruchbetrieb in Grillenburg - als letzter verbliebener cenomanzeitlicher Werksandsteinbruch auf dem Osterzgebirge - endgültig eingestellt (Grunert 1986: S. 110; Beeger und Siedel 2007: S. 40). So ist dieser doch recht kleine Steinbruch am Flügel Jägerhorn das Zeugnis einer - mit Unterbrechungen - immerhin 770 Jahre andauernden Abbautätigkeit nach Werksandsteinen im Tharandter Wald. 


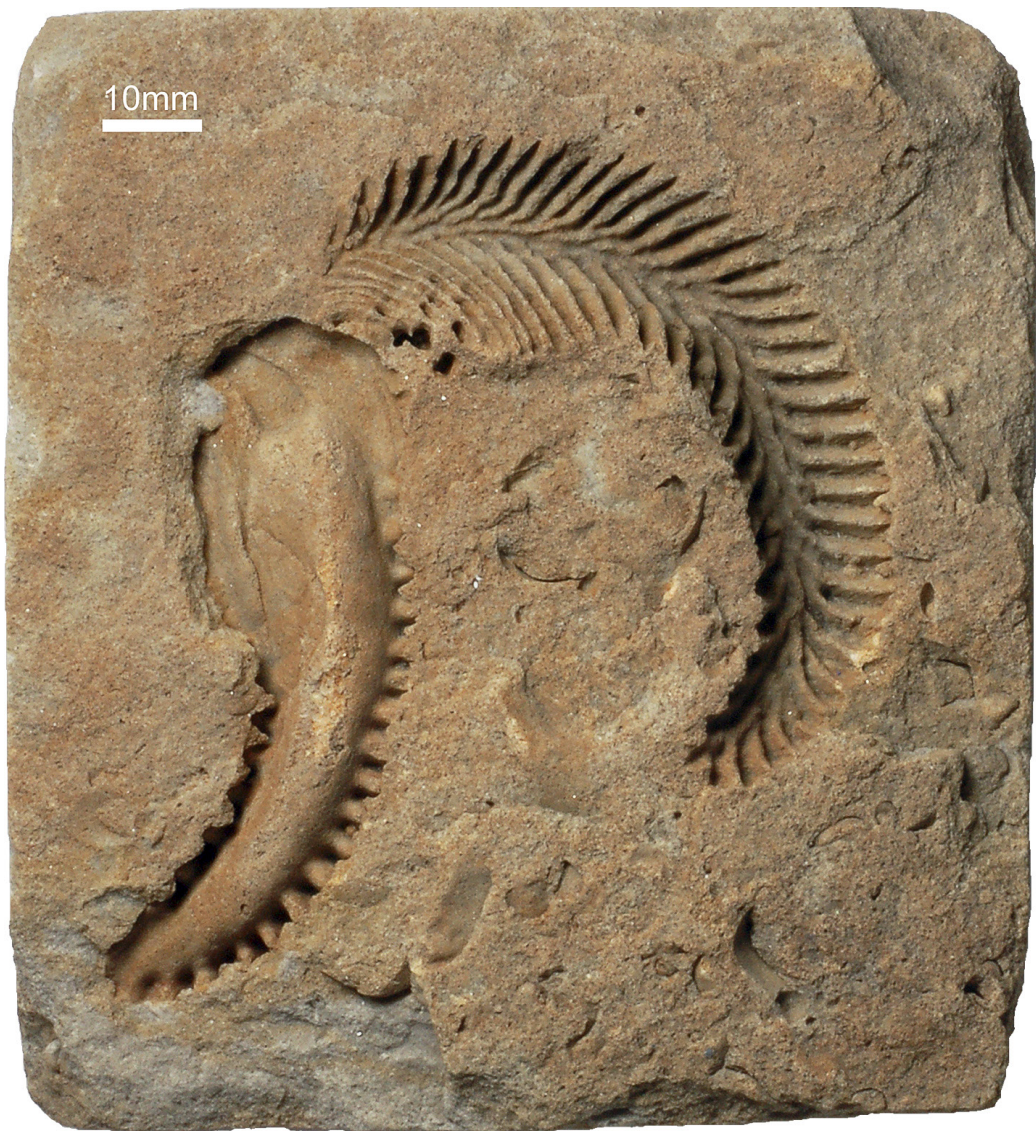

Abbildung 7. Hahnenkamm-Muschel $R a$ stellum carinatum aus der OberhäslichFormation in Dippoldiswalde-Oberhäslich (MMG: SaK 10662 aus den Senckenberg Naturhistorischen Sammlungen Dresden, Museum für Mineralogie und Geologie; Foto: R. Winkler 2014). Die linke Klappe ist als konvexer Steinkern (links) und die rechte Klappe als konkaver Außenabdruck erhalten (rechts oben).

Figure 7. Bivalve Rastellum carinatum from the Oberhäslich Formation in Dippoldiswalde-Oberhäslich (MMG: SaK 10662 in the Senckenberg Natural History Collections Dresden, Museum of Mineralogy and Geology; photo: R. Winkler 2014). The left shell is preserved as a convex mould (left) and the right shell as a concave outer imprint (top right).
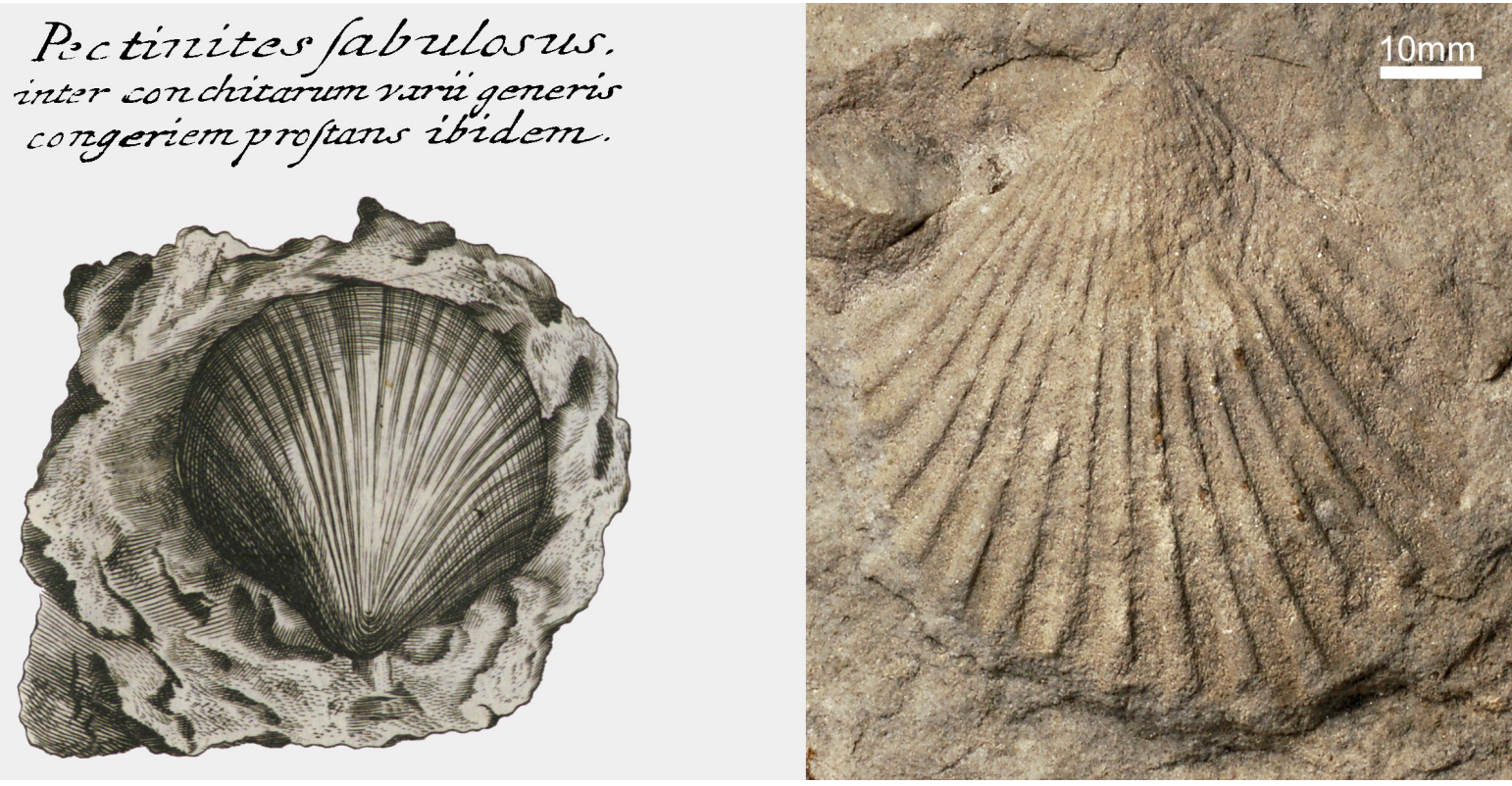

Abbildung 8. Die dritte der bisher bekannten ältesten Abbildungen von Fossilien aus der sächsischen Kreide zeigt links den pectine aurio von Henckel (1722: S. 561, Fig. 1) aus dem Grillenburger Sandstein und stellt die pectinide Muschel Merklinia aspera dar. Das rechts abgebildete Exemplar (MMG: SaK 351 aus den Senckenberg Naturhistorischen Sammlungen Dresden, Museum für Mineralogie und Geologie; Foto: R. Winkler 2014) stammt ebenfalls aus der Oberhäslich-Formation in Dippoldiswalde-Oberhäslich.

Figure 8. The third of the oldest known images of fossils from the Saxonian Cretaceous shows at the left side the pectine aurio of Henckel (1722: p. 561, fig. 1) from the Grillenburg Sandstone, representing the pectinid bivalve Merklinia aspera; the specimen at the right side (MMG: SaK 351 in the Senckenberg Natural History Collections Dresden, Museum of Mineralogy and Geology; photo: R. Winkler 2014) also comes from the Oberhäslich Formation in Dippoldiswalde-Oberhäslich. 


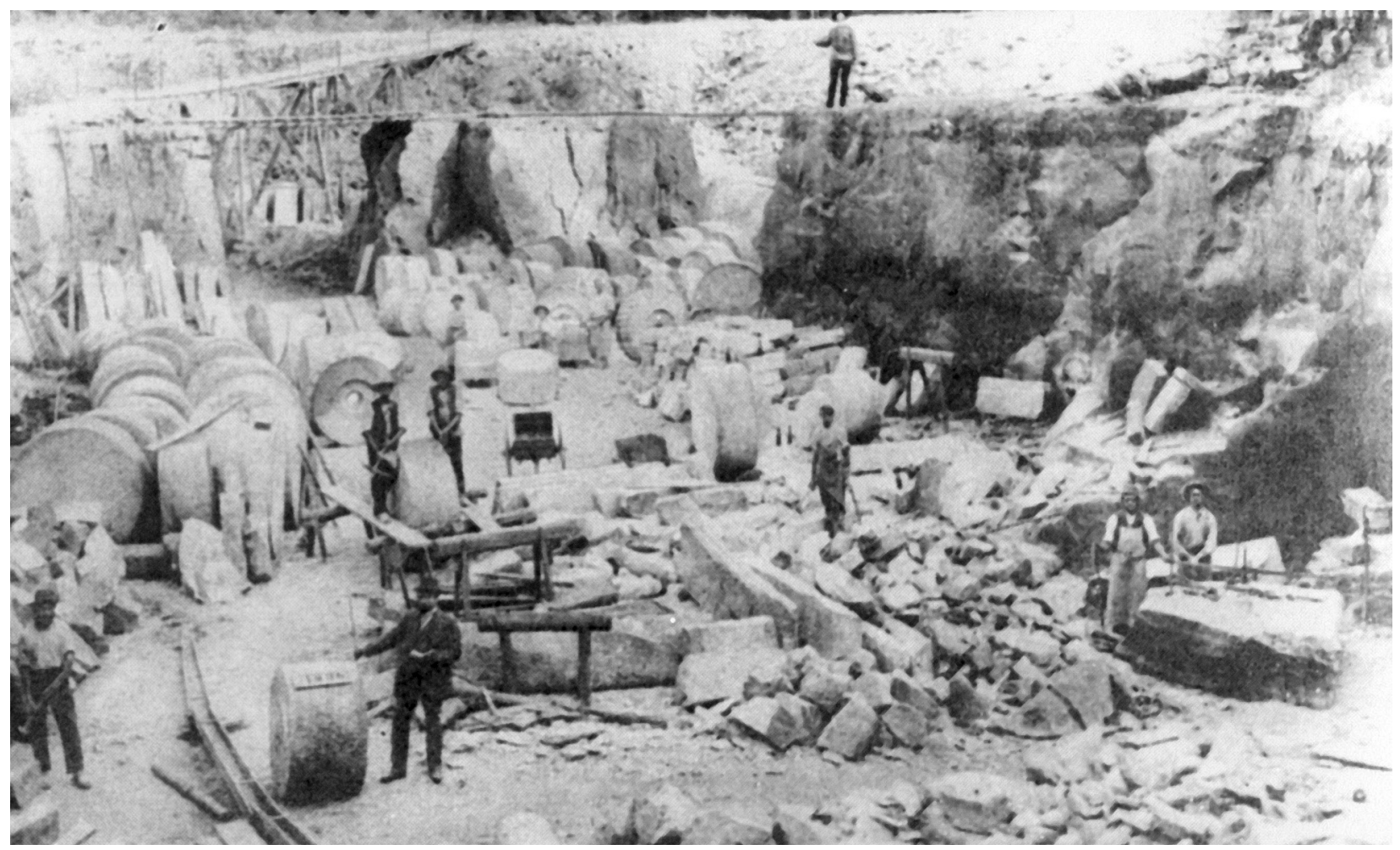

Abbildung 9. Der Grillenburger Sandsteinbruch am Flügel Jägerhorn mit fertig auslieferbaren Schleifsteinen Ende des 19. Jahrhunderts (Foto: G. Rapp 1896. SLUB / Deutsche Fotothek, Nr. df_rp-c_0870056). Die Fotografie zeigt den Bereich des Ohrweiden-Biotops im heutigen Steinbruch Nr. 104 mit Blick nach Westen (vgl. Abb. 15).

Figure 9. The Grillenburg sandstone quarry at the Flügel Jägerhorn with ready-to-deliver whetstones at the end of the $19^{\text {th }}$ century (photo: G. Rapp 1896. SLUB / Deutsche Fotothek, Nr. df_rp-c_0870056). The photography shows the area of the willow tree biotope in the recent quarry no. 104 looking to the west (comp. Fig. 15).

\section{Lithostratigraphie}

Der Sandsteinbruch am Flügel Jägerhorn ist in der geowissenschaftlichen Literatur vielfach erwähnt worden. Die Funde von pecten und insecti marini (Henckel 1722: Fig. 1-3) wurden jedoch von keinem der folgenden Bearbeiter zitiert; der abgebaute Kreidesandstein galt als fossilleer (,enthält keine Spur von Petrefacten“; Sauer 1887: S. 49). Erstmalig wurde das Profil von Freiesleben (1792: S. 123) aufgenommen. Die dort beschriebene lithostratigraphische Abfolge (siehe unten Kapitel Profilaufnahme), an der sich alle folgenden Bearbeiter orientierten, ist bis heute nur unmaßgeblich variiert worden. Erwähnt wird der Steinbruch bei Cotta (1836: S. 54), Naumann und Cotta (1845: S. 365), Sauer (1887: S. 48, Fig. 6), Süß und Weicker (1923: S. 116), Schreiter (1927: S. 78), Reichert (1961: S. 12, Abb. 9), Tröger und Prescher (1963: S. 155) sowie Beeger und Quellmalz (1965: S. 112, 206); petrographisch bearbeitet von Häntzschel (1933, 1934), Prescher (1957), Beeger et al. (1962), Grunert (1986), Götze und Siedel (2004) sowie Siedel et al. (2011); Göhler $(2006 a, b)$ veröffentlichte erstmals eine neue Interpretation des Werksandsteins.

Angaben über die Stratigraphie der Kreide-Schichten, besonders der dort abgebauten ,Werksteinbank“, sind rar. Auf der Suche nach einer Erklärung, warum der Gril- lenburger Werksandstein nicht in der „Oberen Stufe des unteren Quadersandsteins mit dem Pecten asper und der Ostrea carinata“ plaziert wurde, sondern in der „Stufe der Crednerien = Niederschönaer Schichten“, wird man bei Sauer (1887: S. 41) fündig: „Vorausgeschickt sei noch, dass die Sandsteine der marinen Stufe häufig, aber nicht immer einen bald spärlichen, bald reichlichen Glaukonitgehalt aufweisen, dabei im Allgemeinen feinkörniger sind als in der Stufe der pflanzenführenden Schichten und endlich, dass in höchst bemerkenswerther Weise an der Grenze zwischen beiden eine Geröllschicht auftritt, die zuweilen zu einer ansehnlichen Conglomeratbank anschwellen kann." - Und diese drei von ihm angeführten Kriterien, insbesondere das auffällige Rhyolith-Konglomerat, fand Sauer (1887: S. 49) im Sandsteinbruch am Flügel Jägerhorn nun einmal oberhalb, und nicht unterhalb des Werksandsteins! Er schreibt weiter: „Dieselbe [Conglomeratbank] ist offenbar hier die gleiche Grenzschicht zwischen dem unteren Landpflanzen-führenden und oberen marinen Horizonte, wie in den oben mitgetheilten Profilen des Niederschöna'er Gebietes“ (Sauer 1887: S. 49) - entspräche also in Niederschöna dem Transgressionskonglomerat der mittleren Oberhäslich-Formation (nach Wilmsen et al. 2022) auf der kontinentalen Niederschöna-Formation. Die Ansicht wird von Schreiter (1927: S. 78) übernommen und war seitdem festgeschrieben: „Diese Werksteinbank gehört wiederum 


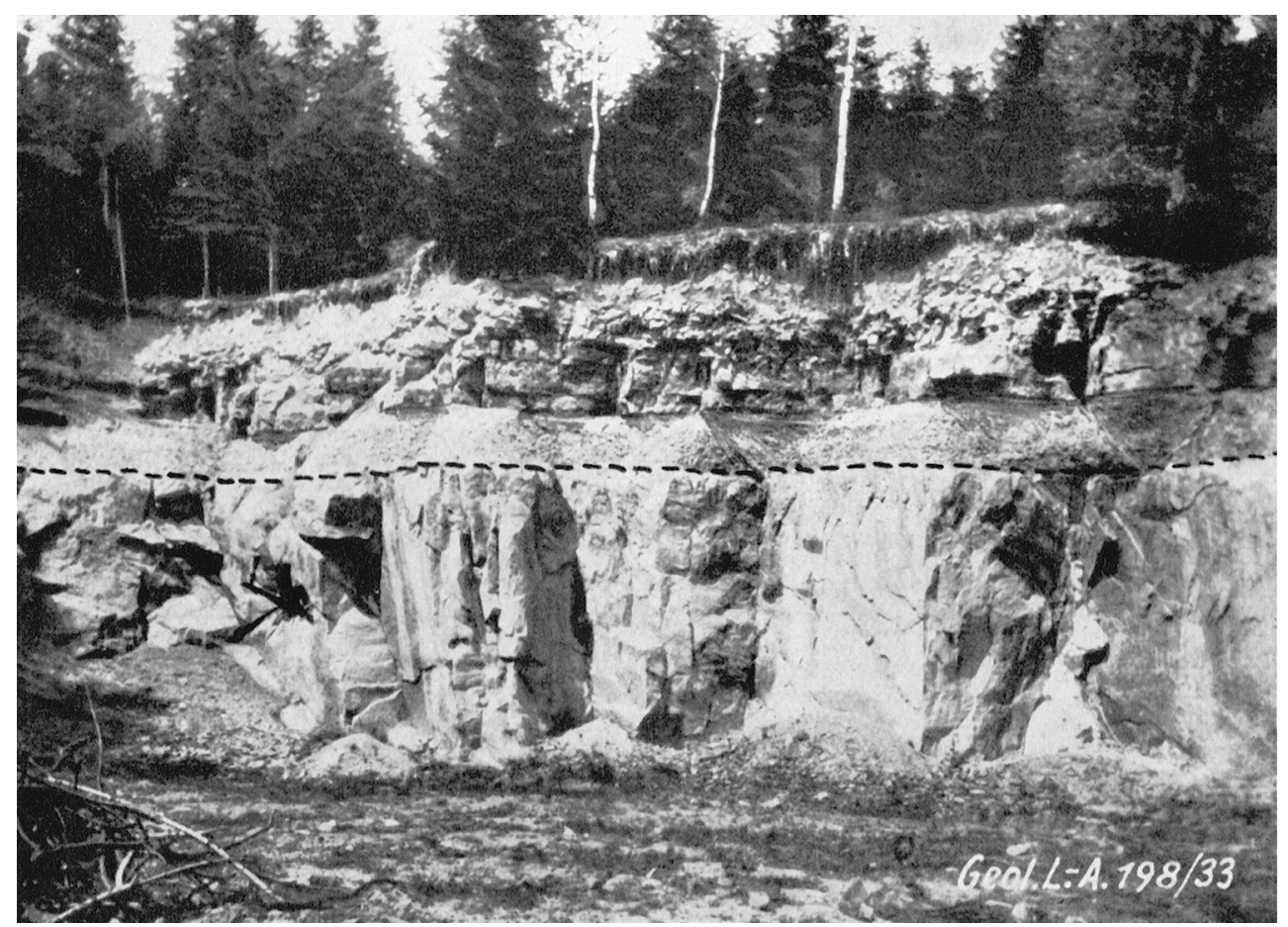

Plänersandstein

Toniger Sandstein Porphyr-Konglomerat

Crednerien Sandstein

Abbildung 10. Profil im Sandsteinbruch am Flügel Jägerhorn (Nordwand des heutigen Bruchs Nr. 104). „Die gestrichelte Linie bezeichnet die Oberkante der terrestrischen Crednerien-Sandsteine“ (aus Häntzschel 1933: Taf. 2, Fig. 4; Foto: A. Seifert 1931). Nach unserer Einstufung entspricht sie der Dachfläche des Werksandsteins der Oberhäslich-Formation.

Figure 10. Section of the sandstone quarry at the Flügel Jägerhorn (northern wall of the recent quarry no. 104). "The dashed line marks the upper edge of the terrestrial Crednerian Sandstones" (from Häntzschel 1933: pl. 2, fig. 4; photo: A. Seifert 1931). According to our classification, it corresponds to the top surface of the Werksandstein of the Oberhäslich Formation..

dem nichtmarinen Quadersandstein der Niederschönaer Stufe an."

Häntzschel (1933, 1934) interpretiert den angeblich fossilfreien Grillenburger Werksandstein aufgrund der Korngrößenverteilung und guten Sortierung als einen äolisch sedimentierten Sandstein. Er parallelisiert ihn mit dem ,jüngsten Glied der Crednerien-Schichten“ an der Typuslokalität der Niederschöna-Formation (Abb. 10), obwohl er die am Forsthaus Niederschöna zu beobachtenden pflanzlichen Röhren-Systeme der Wurzelböden im Liegenden des marinen Cenomaniums (siehe Häntzschel 1933: Taf. 2, Fig. 1; Voigt 1998: Abb. 15; Eberlein 2004: Abb. 5.35b, 5.36b, Anl. IV, Taf. 5.3, Foto 5) am Flügel Jägerhorn nicht nachweisen konnte. Auch übernimmt er die bei Sauer (1887: S. 49) angegebene stratigraphische Position des Rhyolith-Konglomerats: „Da die Hangend-Schichten dieses Profils der Plenus-Zone, die liegenden Sandsteine jedoch den Crednerien-Schichten zuzurechnen sind, ergibt sich, daß der fehlende marine Carinaten-Quader wohl durch die Konglomerate ersetzt wird" (Häntzschel 1933: S. 16). - Und so war es im Sommer 2020 noch auf der Informationstafel im Steinbruch zu lesen.

Auch bei Prescher (1957: S. 27) gehören die „Albsandsteine“ zu den „feinkörnigen, äolisch gebildeten Sandsteinen“ der „Niederschönaer Schichten“. Dies wurde auch durch petrographisch-lithofazielle Untersuchungen gestützt, die unter anderem aufgrund des Abrollungsgrades der detritischen Quarzkörner zu dem Ergebnis kommen, dass die „Kornklasse 4a (im Wind oder Wasser bewegter Sand; Dünen-, Fluß- und Strandsand)“ und die
„Kornklasse 4b (im Wind bewegter Sand; Dünensand)“ im Grillenburger Sandstein entwickelt sind (Prescher 1957: S. 74; Beeger et al. 1962: S. 95). Weiterhin meint Prescher (1957: S. 27, 53) die in Niederschöna bekannten „vom Sand verschütteten oberirdischen Pflanzenteile“ auch in der Grillenburger „Werksteinbank“ beobachtet zu haben. Grunert (1986: S. 109, 113) hält den Sandstein der „Werksteinbank im Steinbruch am Flügel Jägerhorn“ aufgrund seiner Gleichkörnigkeit und hohen Festigkeit für eine „Ausnahme“ unter den lediglich als Bauware genutzten heterogenen Niederschönaer Sandsteinen und erwähnt; „Sehr vereinzelt kommen Röhren vor, die mit etwas gröberem Material ausgefüllt sind“. Erstmalig Göhler (2006a) interpretiert den Werksandstein am Flügel Jägerhorn korrekt als , die litorale Fazies des unteren Obercenomans (Oberhäslich-Formation)“, beschreibt jedoch - vermutlich in Anlehnung an die Untersuchungen von Beeger et al. (1962) - das untere $3 / 4$ als eine ,schwer trennbare Wechselschichtung marin und äolisch gebildeter Sandsteine", denen als oberster Abschnitt ein etwa $1 \mathrm{~m}$ mächtiger „massiger Sandstein (wahrscheinlich Flugsanddecke)“ aufliegt. [Die Oberhäslich-Formation besteht jedoch seit ihrer ersten Definition ausschließlich aus vollmarin abgelagerten Sandsteinen; vgl. Niebuhr et al. (2007).] Siedel et al. (2011) liefern eine petrographisch-gesteinstechnische Charakterisierung von Sachsens Bausandsteinen, auch des „Grillenburger Sandsteins aus der Werksteinbank des Steinbruchs Grillenburg“. In der 3. Auflage der geologischen Karte 1:25.000, Blatt 5047 Freital (Alexowsky et al. 2012) wird die „Werk- 
steinbank" erneut in der fluviatilen Niederschöna-Formation des Unter- und Mittelcenomaniums geführt.

Seit nunmehr über 130 Jahren ist allen Interpretationen gemeinsam, dass der Grillenburger Werksandstein nicht als das angesehen wird, was er unserer Meinung nach ist: der Werksandstein der oberen Oberhäslich-Formation an allen bekannten Lokalitäten ohne Tonlagen, Wurzelhorizonte, Pflanzenfossilien und Kohlen (wie sie für die kontinentale Niederschöna-Formation typisch sind; Voigt 1998; Niebuhr und Wilmsen, in Vorber.), dafür aber mit verschiedenen Muscheln (die teilweise massenhaft besonders im unteren Profilabschnitt der mittleren Oberhäslich-Formation auftreten) und marinen Spurenfossilien (Wilmsen 2017; Niebuhr et al., siehe unten Abb. 13).

Die erstmals von Schander (1924) geäußerte Interpretation der „groben, kreuzgeschichteten Sandsteine“ bei Niederschöna als „Dünensande“ hält sich hartnäckig bis heute, ist aber falsch. Bemerkenswert ist allerdings, dass dort ein wichtiges Charakteristikum von Dünensanden korrekt genannt wird. So sind sie meist großdimensional schräggeschichtet [,,die öfter erwähnte, ausgezeichnet sichtbare starke Diagonalschichtung großen Maßstabs, die eine alte Dünenstruktur noch deutlich erkennen läßt", Schander (1924: S. 115)]. Dieser wichtige Hinweis wurde von den folgenden Bearbeitern bei der Übertragung der Niederschönaer Dünensand-Interpretation auf die massigen, bioturbat vollständig entschichteten Werksandsteine der oberen Oberhäslich-Formation außer Acht gelassen.

Äolische Sedimente existieren in der sächsischen Kreide nicht (cf. Voigt 1994, 1998). Die Wurzelböden im Typusprofil Forsthaus Niederschöna (Häntzschel 1933: Taf. 2, Fig. 1; Eberlein 2004: Abb. 5.35b, 5.36b, Anl. IV, Taf. 5.3) stellen typische Auensedimente dar, in denen jede Hochwasserlage des „Niederschönaer Flusses“ durch eine nach oben feiner werdende Sand-Ton-Abfolge abgebildet wird. Die senkrechten, maximal $50 \mathrm{~cm}$ langen, dicht-an-dicht-stehenden und 2-5 mm dünnen Röhren, glattgewandet, hohl oder mit kohliger Substanz gefüllt, laufen an den Spitzen aus (Häntzschel 1933: S. 11) und gehen vermutlich auf eine schilfartige Pflanze zurück (cf. Voigt 1998: S. 130, Abb. 15). Es herrschte im Cenomanium ein extremes Treibhausklima mit ständigen, ausgiebigen Regenfällen, wie die üppigen Landpflanzen aus der Niederschöna-Formation belegen (Ettingshausen 1867). Diese Befunde stehen der Entstehung von Dünen stark entgegen und auch die Ausbildung lokaler Dünensandsteine ist unter diesen Bedingungen unwahrscheinlich.

\section{Profilaufnahme}

Der ersten, sehr präzisen Schichtenbeschreibung des Sandsteinbruchs am Flügel Jägerhorn (Freiesleben 1792: S. 123), damals noch vom Hangenden ins Liegende, gibt es nur wenig hinzuzufügen: „Der interessanteste Bruch in diesem Gebirge liegt in dem Grüllenburger Forste, im Buchstaben W; er ist churfürstlich, dermalen aber verpachtet. Die einzelnen Schichten in demselben, welche alle söhlig liegen, sind folgende 4:

1) ein sehr zerklüftetet, in lauter parallellopipedische Stücke zerspaltener Sandstein, welcher meist 3 Ellen $[\hat{=} 3,40 \mathrm{~m}]$ stark ist.

2) ein bunter weicher Sandstein, mit eingemengten Porphirtheilchen; er ist meist schmutzig lauch- und olivgrün, doch wechseln auch gelbe Streifen, die sich endlich ins grüne verlaufen, mit ihm ab. Diese Schicht ist ohngefähr $11 \frac{2}{2}$ Elle $[\hat{=} 1,70 \mathrm{~m}$ ] stark.

3) ein Konglomerat, ohngefähr $1 / 2$ bis $3 / 4$ Elle [60-86 cm] stark. Es besteht meisst aus Porphirkieseln, die mit dem in der vorherigen Schicht eingemengten Porphir gleichartig sind, und eine blaß pfirsichblütrothe thonige Hauptmasse haben, in welcher die nämlichen Theile und auch in dem nämlichen Verhältnisse eingemengt sind, wie in dem kurz zuvor beschriebenen Porphire. Die Geschiebe haben höchstens 4 bis 5 Zoll [^ $10-13 \mathrm{~cm}$ ] im Durchmesser, sind rundlich und meist glatt. Merkwürdig und aufklärend für die Entstehung dieser Gebirgsart ist es, daß die größten immer unten, und zunächst der folgenden Schicht liegen. Außer den Porphirgeschieben fanden sich blos noch sehr wenige und kleine Quarzkiesel. Das Bindemittel dieses Konglomerates, ist wie bei den vorherigen Flößen, sehr tonig. Noch ist zu bemerken, daß in dieser Schicht, und zwar nach oben zu, eine $1 / 2$ Zoll [스 $1,3 \mathrm{~cm}$ ] starke Lage von sehr zerklüftetem, aber schönem gelblich braunen Bol erscheint, in dessen Klüften sich ein sehr fetter eisenschüssiger Thon findet.

4) der gute und eigentliche Sandstein. Er ist feinkörnig, gelblichweiß von Farbe, aber mit ziemlich häufigen braunen Flecken und Streifen. Sein Bindemittel ist zwar noch thonig, er wird aber niederzu immer fester, und wie es scheint quarziger. Er ist dermalen 5 bis 6 Ellen $[\hat{=} 5,70$ $6,85 \mathrm{~m}$ ] abgebauet. Die besten und meisten Steine werden an der N W Seite des Steinbruchs gebrochen. Zerklüftet ist diese Schicht wenig, und wo sie es ist, blos senkrecht.“

Nach unserer Aufnahme (Abb. 11) beginnt das Profil an der Basis mit der über 5 m mächtigen ,Werksteinbank“ (Abschnitt 1 in Abb. 12a). Dieser homogene, massige Sandstein ist vollständig bioturbat entschichtet und zeigt in der gesamten anstehenden Mächtigkeit weder Schichtfugen, Schrägschichtung noch andere Sedimentstrukturen; Tonlagen treten ebenfalls nicht auf. Der Werksandstein ist ein sehr reiner, weiß bis gelblicher Quarzsandstein (Proben FJ 1 und 2 auf Abb. 12d, e) mit über 99\% Quarz, unter 0,2\% Schwermineralen und sehr wenig Glimmer; 75-85\% der Quarzkörner liegen in der Korngröße 0,2-0,5 mm vor, was einem Mittelsandstein entspricht (Häntzschel 1934; Prescher 1957; Beeger et al. 1962). Die gut gerundeten Quarze sind mittels konkavokonvexer Kornkontakte nur moderat kieselig bis kieselig-limonitisch verbunden und zeigen häufig syntaxiale Anwachssäume, die glitzernde, sekundäre Kristallflächen auf den vormals abgerollten, detritischen Quarzkörnern hervorbringen; der Porenraum (Porosität ca. 25\%; Siedel et al. 2011) ist kaum gefüllt. Im oberen Werksand- 


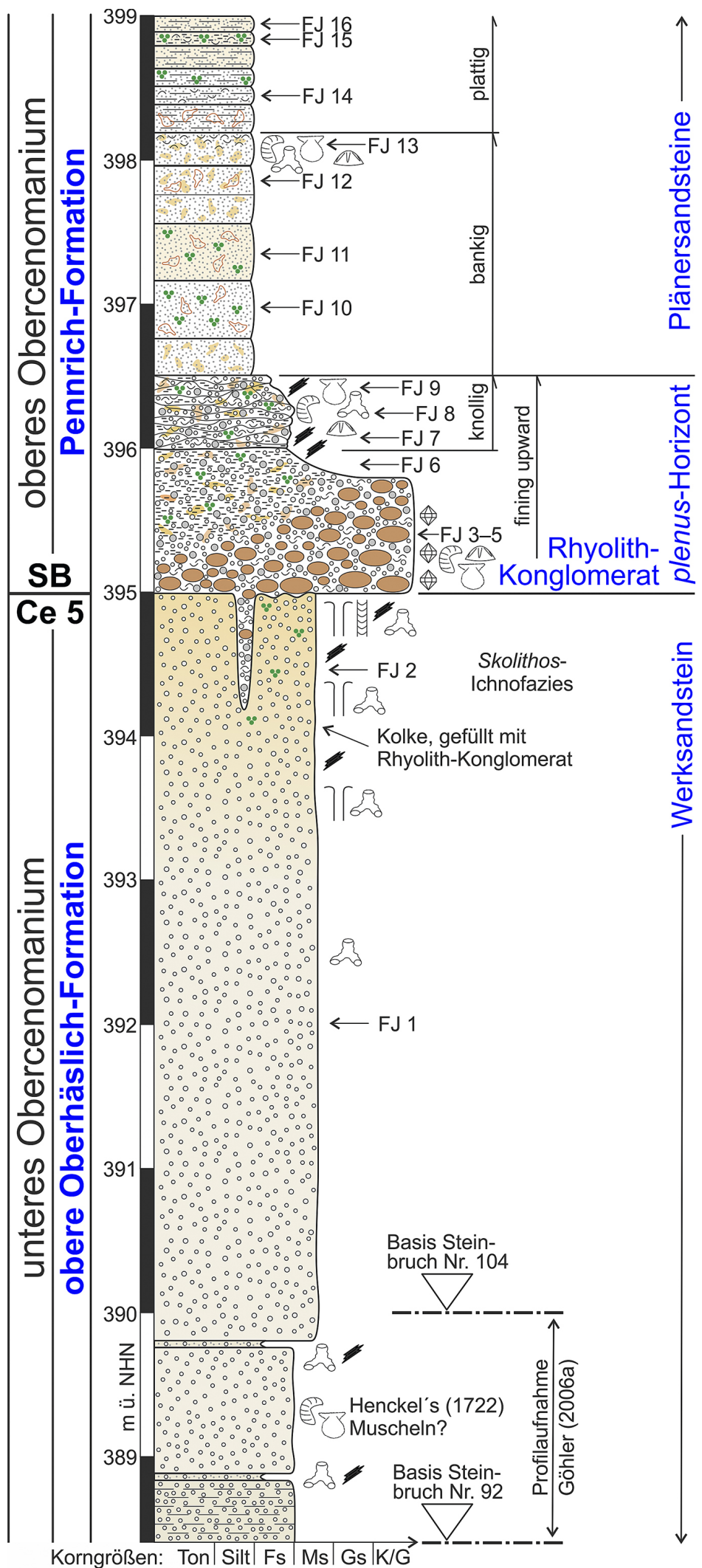

Abbildung 11. Korngrößen-basiertes Profil des Sandsteinbruches am Flügel Jägerhorn westlich von Grillenburg. Das bekannte Rhyolith-Konglomerat, das im alten Steinbruch Nr. 92 eine ca. $80 \mathrm{~cm}$ mächtige, massive Bank aufbaut, ist im östlichen Abschnitt des heutigen Steinbruchs Nr. 104 nur noch ca. 25 cm mächtig. Korngrößen (unten): Ton $(<0,002 \mathrm{~mm})$, Silt $(0,002-0,063 \mathrm{~mm}), \mathrm{Fs}=$ Feinsand $(0,063-0,2 \mathrm{~mm}), \mathrm{Ms}=$ Mittelsand $(0,2-0,63 \mathrm{~mm}), \mathrm{Gs}=$ Grobsand $(0,63-2 \mathrm{~mm}), \mathrm{K} / \mathrm{G}=\mathrm{Kies} /$ Geröll $(>2 \mathrm{~mm})$. Legende siehe Abb. 1.

Figure 11. Grain-size-based section of the sandstone quarry at the Flügel Jägerhorn, west of Grillenburg. The famous rhyolite conglomerate that appears as a massive, 80-cm-thick layer in the old quarry no. 92, reaches only ca. $25 \mathrm{~cm}$ in the recent quarry no. 104. Grain sizes (below): clay $(<0.002 \mathrm{~mm})$, silt $(0.002-0.063 \mathrm{~mm}), \mathrm{Fs}=$ fine-grained sand $(0.063-0.2 \mathrm{~mm}), \mathrm{Ms}=$ medium-grained sand $(0.2-0.63 \mathrm{~mm}), \mathrm{Gs}=$ coarse-grained sand $(0.63-2 \mathrm{~mm}), \mathrm{K} / \mathrm{G}=$ gravel/boulder $(>2 \mathrm{~mm})$. Legend see Fig. 1. 


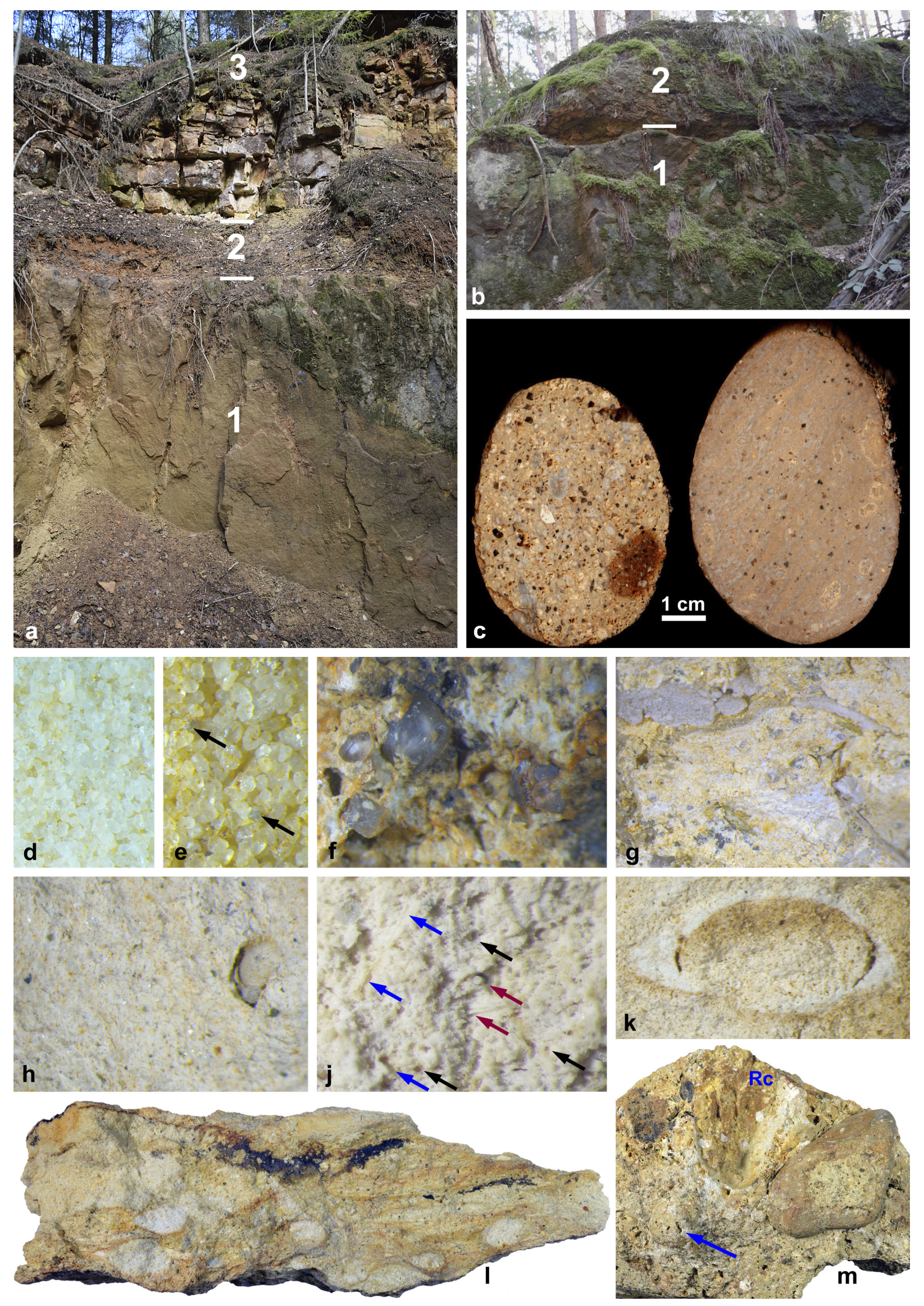


Abbildung 12. Gesteinsaufnahmen aus dem Sandsteinbruch am Flügel Jägerhorn. a, d, f-m heutiger Steinbruch Nr. 104; b, c, e alter Steinbruch Nr. 92; d-m Aufnahmen frisch gebrochener Gesteinsoberflächen (Fotos: B. Niebuhr 04/2021). a Gesamtansicht der Kreidesandsteine an der Westwand, Profilhöhe ca. $8 \mathrm{~m}$; 1: Werksandstein der oberen Oberhäslich-Formation mit planarer Dachfläche; 2: tonige Mittel- bis Grobsandsteine mit dem Rhyolith-Konglomerat an der Basis, plenus-Horizont der unteren Pennrich-Formation; 3: gut gebankte, spiculitische Siltsteine (Plänersandsteine der mittleren Pennrich-Formation) (Foto: M. Wilmsen 2021). b Sequenzgrenze SB Ce 5, Bildbreite ca. 3 m; 1: Werksandstein der oberen Oberhäslich-Formation mit welliger Dachfläche; 2: grobes Rhyolith-Konglomerat als $80 \mathrm{~cm}$ mächtige, massive Bank (Foto: B. Niebuhr 04/2021). c polierte Oberfläche von wenig verwitterten Rhyolith-Geröllen aus dem Transgressionskonglomerat der Pennrich-Formation; links: phenokristallreicher Rhyolith („quarzreicher Porphyr") und rechts: phenokristallarmer Rhyolith in Ignimbrit-artiger Entwicklung („quarzarmer Porphyr") aus der Tharandter-Wald-Caldera (Fotos: F. Haubrich 2020). d FJ 1, sehr gut sortierter, mittelkörniger Quarzsandstein mit kieseligem Zement, Werksandstein der oberen Oberhäslich-Formation, Bildbreite 7,5 mm. e FJ 2, sehr gut sortierter, mittelkörniger Quarzsandstein mit wenig hell-gelblichgrünem Glaukonit (Pfeile) und kieselig-limonitischem Zement, Werksandstein der oberen Oberhäslich-Formation, Bildbreite 3,8 mm. f FJ 3, idiomorphe Quarzdihexaeder in einem glaukonitführenden, tonigen Grobsandstein, Rhyolith-Konglomerat der basalen Pennrich-Formation, Bildbreite 7,5 mm. g FJ 7, knollige, glaukonitische Feinsandsteine mit vielen verkieselten Bioklasten, untere Pennrich-Formation, Bildbreite $15 \mathrm{~mm}$. h FJ 10, stark verkieselter, spiculitischer Siltstein mit Glaukonit und vielen, großen Hellglimmern sowie Lösungshohlräume kleiner Bioklasten (rechts), mittlere Pennrich-Formation, Bildbreite 7,5 mm. j FJ 13, monaxone Megaskleren als kreisrunde Löcher (schwarze Pfeile), teilweise mit sekundär verkieselter Füllung der Innenkanäle (rote Pfeile), oder in Längserstreckung (blaue Pfeile) im spiculitischen Siltstein, mittlere Pennrich-Formation, Bildbreite 5,8 mm. k FJ 10, augenförmige Verkieselung um einen kompaktierten Krebsgang herum (?Thalassinoides suevicus), mittlere Pennrich-Formation, Bildbreite 11 mm. I FJ 8, gelbfleckiger, inhomogener Fein- bis Mittelsandstein mit Glaukonit, großen isolierten Quarzkörnern, vielen Holzresten und weißen, feinsandig gefüllten Krebsgängen, untere Pennrich-Formation, Bildbreite $17 \mathrm{~cm}$. m FJ 4, Transgressionskonglomerat der basalen Pennrich-Formation mit kaum verwittertem Rhyolith-Geröll (rechts) und vollständig kaolinisiertem Geröll (links, Pfeil), zwischen beidem eine verkieselte Schale von Rastellum carinatum (Rc), Bildbreite $8 \mathrm{~cm}$.

Figure 12. Rock photographs from the sandstone quarry at the Flügel Jägerhorn. a, d, f-m, recent quarry no. 104; b, c, e old quarry no. 92; d-m images of fresh-brocken rock surfaces (photos: B. Niebuhr 04/2021). a General view of the Cretaceous sandstones at the western wall, section height ca. $8 \mathrm{~m}$; 1: sandy freestone of the upper Oberhäslich Formation with planar top surface; 2: clayey, medium- to coarse-grained sandstones with the rhyolite conglomerate at the base, plenus horizon of the lower Pennrich Formation; 3, well bedded, spiculitic-glauconitic siltstones (Pläner Sandstones of the middle Pennrich Formation) (photo: M. Wilmsen 2021). b Sequence boundary SB Ce 5, width of photo ca. $3 \mathrm{~m}$; 1: sandy freestone of the upper Oberhäslich Formation with wavy top surface; 2: coarse rhyolite conglomerate as $80 \mathrm{~cm}$ thick, massive bed (photo: B. Niebuhr 04/2021). c polished surface of rhyolite cobbles from the transgression conglomerate of the Pennrich Formation; left: phenocrystalline rhyolite ("quartz-rich porphyry") and right: phenocrystalline rhyolite in ignimbrite-like development ("quartz-poor porphyry") from the Tharandter Wald Caldera (photo: F. Haubrich 2020). d FJ 1, very well sorted, medium-grained quartz-sandstone with siliceous cement, sandy freestone of the upper Oberhäslich Formation, width of photo $7.5 \mathrm{~mm}$. e FJ 2, very well sorted, medium-grained quartz-sandstone with a few light yellow-greenish glauconite (arrows) and siliceous-limonitic cement, sandy freestone of the upper Oberhäslich Formation, width of photo 3,8 mm. f FJ 3, idiomorphic quartz-dihexaeder in a glauconite-bearing, clayey coarse-grained sandstone, rhyolite conglomerate of the basal Pennrich Formation, width of photo $7.5 \mathrm{~mm}$. g FJ 7, nodular, glauconitic fine-grained sandstone with several silicified bioclasts, lower Pennrich Formation, width of photo $15 \mathrm{~mm}$. h FJ 10, strongly silicified, spiculitic siltstone with glauconite and several, large white mica flakes as well as dissolved cavities of small bioclasts (right), middle Pennrich Formation, width of photo $7.5 \mathrm{~mm}$. j FJ 13, monaxone megascleres of siliceous sponges visible as circular holes (black arrows), partly with secondary silicified filling of their internal cavities (red arrows), or in longitudinal extension (blue arrows) in a spiculitic siltstone, middle Pennrich Formation, width of photo $5.8 \mathrm{~mm}$. k FJ 10, eye-shaped silicification around a compacted crustacean burrow (?Thalassinoides suevicus), middle Pennrich Formation, width of photo $11 \mathrm{~mm}$. I FJ 8, yellow-stained, inhomogeneous fine- to medium-grained sandstone with glauconite, large isolated quartz grains, several wood remains and white crustacean burrows filled with fine-grained sand, lower Pennrich Formation, width of photo $17 \mathrm{~cm}$. m FJ 4, transgression conglomerate of the basal Pennrich Formation with scarcely weathered rhyolite pebble (right) and completely kaolinizied pebble (left, arrow), between both a silicified shell of Rastellum carinatum (Rc), width of photo $8 \mathrm{~cm}$. 

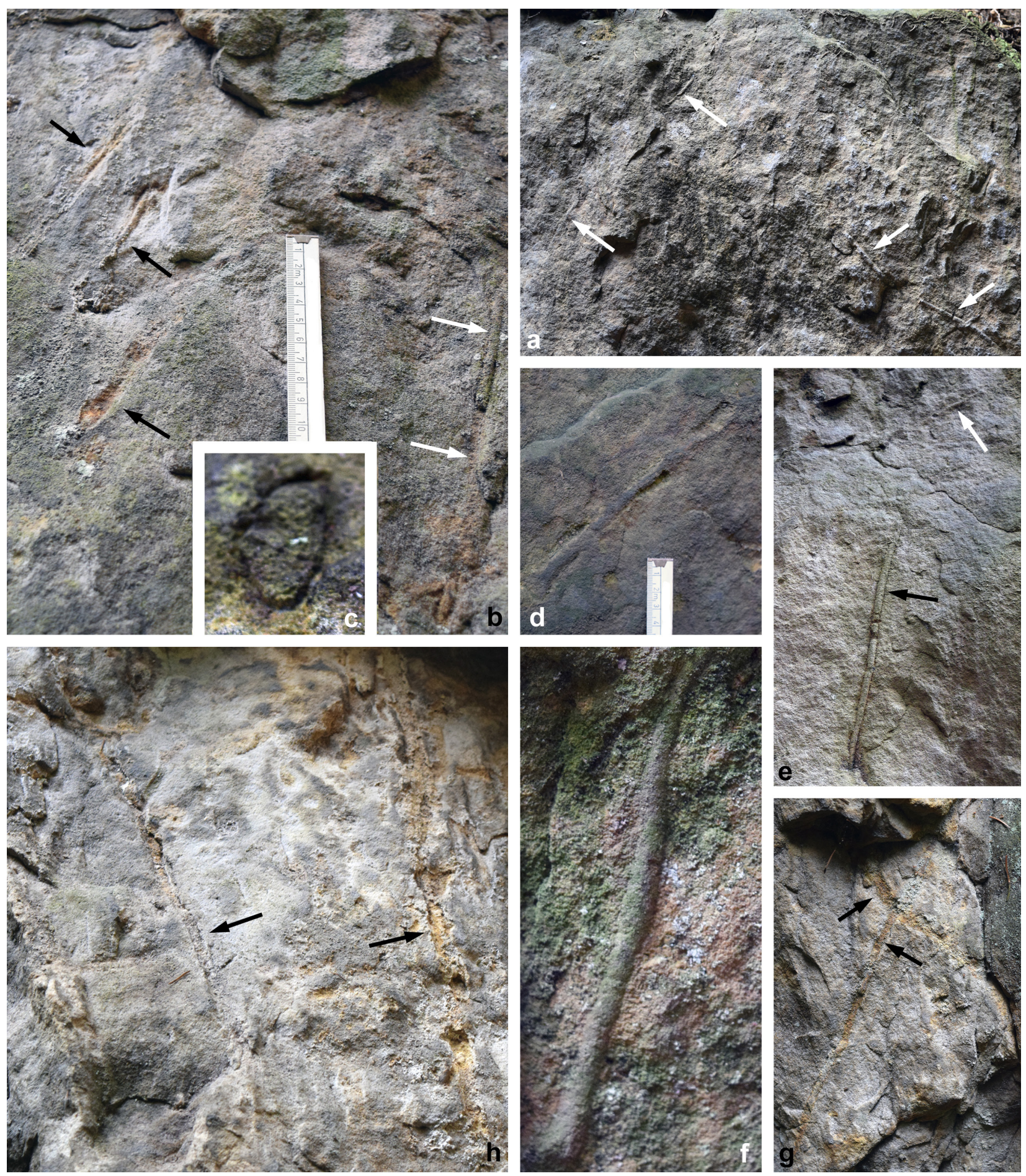

stein-Abschnitt des alten Steinbruchs Nr. 92 wurde wenig hell-gelblichgrüner Glaukonit (Probe FJ 2 auf Abb. 12e) und viel inkohlte Pflanzenhäcksel gefunden.

Neben den erwähnten Muscheln Rastellum carinatum und Merklinia aspera (siehe Abbildungen von Henckel 1722; hier Abb. 6, 8 links), vermutlich aus dem unteren, heute nicht mehr aufgeschlossenen Profilabschnitt im alten Steinbruch Nr. 92 (vgl. Göhler 2006a), wurden besonders in den obersten 1,50-2 $\mathrm{m}$ des heutigen Steinbruchs Nr. 104 mindestens fünf verschiedene marine Spurenfossilien gefunden: Ophiomorpha saxonica (Abb. 13c) zeigt eine genoppte Wandstruktur, wohingegen Thalassinoides suevicus (Abb. 13d, g) einen glatten Wandaufbau hat, der oftmals durch Limonit-Häutchen nachgezeichnet wird (Abb. 12k, 1). O. saxonica und T. suevicus sind offene Röhrensysteme, die auf die Grabungstätigkeit von Zehnfußkrebsen (Dekapoda) zurückgehen; ihre Schäfte verlaufen annähernd senkrecht, in schichtparallelen Netzwerken verzweigen sich die Gänge bei beiden Y-förmig (Niebuhr und Wilmsen 2016). Die geraden, nur wenige Millimeter dünnen Spuren, die mit $30-60^{\circ}$ zur Schichtung verlaufen und sich nie verzweigen oder berühren (Abb. 13a, e oben), könnten unter Vorbehalt zu ?Palaeophycus tubularis gestellt werden. Eine Bestimmung solch merkmalsarmer Spurenfossilien gestaltet sich jedoch schwierig. Diese drei Spurenfossilien treten auch in ande- 


\begin{abstract}
Abbildung 13. Marine Spurenfossilien aus den obersten 1,50-2 $\mathrm{m}$ des Werksandsteins im Sandsteinbruch am Flügel Jägerhorn, senkrecht zur Schichtung aufgenommen (Fotos: M. Wilmsen 2021). a Mehrere ?Palaeophycus tubularis in unterschiedlichen Winkeln zur Schichtung, die obere Bildkante zeigt die wellige Dachfläche des Werksandsteins; Bildbreite $23 \mathrm{~cm}$. b Links drei Taenidium-cameronensis-Spuren mit meniskusförmigen Querstopfstrukturen (schwarze Pfeile), rechts eine Skolithos-linearis-Röhre (weiße Pfeile); Bildbreite $57 \mathrm{~cm}$. c Schräg angeschnittener Ophiomorpha-saxonica-Gang, Bildhöhe $3 \mathrm{~cm}$. d Thalassinoides-suevicus-Gang; Bildbreite $15 \mathrm{~cm}$. e Unten eine Skolithos-linearis-Röhre, oben rechts ?Palaeophycus tubularis; Bildhöhe $43 \mathrm{~cm}$. f Leicht geschwungene Skolithos-linearis-Röhre, Bildhöhe $14 \mathrm{~cm}$. g Ein gerader und ein leicht gebogener Thalassinoides-suevicus-Schaft, die sich im rechten Winkel kreuzen, Bildhöhe $26 \mathrm{~cm}$. h Zwei Skolithos-linearis-Röhren, die von der Dachfläche des Werksandsteins herunterführen; Bildhöhe $41 \mathrm{~cm}$.
\end{abstract}

Figure 13. Marine trace fossils from the uppermost 1.50-2 $\mathrm{m}$ of the sandy freestone in the sandstone quarry at Flügel Jägerhorn, figured perpendicular to the bedding (photos: M. Wilmsen 2021). a Several ?Palaeophycus tubularis in different angles to the bedding plane, the upper edge of the picture shows the wavy top surface of the sandy freestone; width of image $23 \mathrm{~cm}$. b Three Taenidium cameronensis traces to the left with meniscate backfill-structures (black arrows), to the right a Skolithos linearis tube (white arrows); width of image $57 \mathrm{~cm}$. c Obliquely-cut Ophiomorpha saxonica burrow, height of image $3 \mathrm{~cm}$. d Thalassinoides suevicus burrow; width of image $15 \mathrm{~cm}$. e Below a Skolithos linearis tube, in the upper right ?Palaeophycus tubularis; height of image $43 \mathrm{~cm}$. f Weakly curved Skolithos linearis tube, height of image $14 \mathrm{~cm}$. g A straight and a weakly curved Thalassinoides suevicus shaft, crossing at right angles; height of image $26 \mathrm{~cm}$. h Two Skolithos linearis tubes that were piped downwards from the top surface of the sandy freestone; height of image $41 \mathrm{~cm}$.

ren oberkretazischen sandig-flachmarinen Ablagerungsräumen gemeinsam auf (Chrząstek 2013). Taenidium cameroniensis (Abb. 13b links) ist ebenfalls unverzweigt, besitzt meniskusförmige Querstopfstrukturen und wird als Spur eines sedimentfressenden Organismus interpretiert. Dünne, lange Skolithos-linearis-Wohnbauten (Abb. $13 \mathrm{~b}$ rechts, e, h) verlaufen ebenfalls annähernd senkrecht zur Schichtung und verzweigen sich nie; als Erzeuger werden wurmähnliche, polychaete Anneliden angenommen. Zusammengenommen charakterisiert diese Spurenfossil-Assoziation mit ihrer Dominanz von einfachen, unverzweigten und überwiegend senkrechten Spuren die Skolithos-Ichnofazies des sandig-flachmarinen und hochenergetischen Ablagerungsraumes oberhalb der Sturmwellenbasis (cf. Seilacher 1967). Wird S. linearis am Top massiger kretazischer Quadersandsteine mit $O$. saxonica gefunden, wie z. B. am Horkenberg bei Bannewitz oder im Lohmgrund bei Dohma-Cotta, wird dies als ichnologische Signatur eines Meeresspiegelrückgangs (Regression) gewertet (Janetschke und Wilmsen 2014; Niebuhr und Wilmsen 2016).

Bei einigen Ophiomorpha- und Thalassinoides-Gängen ist die Füllung etwas grobkörniger als das umgebende Sediment, was auf die Bildung als Röhrentempestite (tubular tempestites) hindeutet. Dabei werden die weit verzweigten, offenen Gangsysteme der Zehnfußkrebse während einer Sturmflut mit erodierter, ursprünglich küstennäher abgelagerter Bodenfracht verfüllt (Niebuhr und Wilmsen 2016: S. 200, Abb. 7e, f, 8). Im Gegensatz zu den spitz zulaufenden und hohlen, pflanzlichen Röhren der fluviatilen Niederschönaer Wurzelhorizonte (Häntzschel 1933: S. 11, Taf. 2, Fig. 1) sind die marinen Spurenfossilien der sächsischen Kreide immer verfüllt (vgl. Niebuhr und Wilmsen 2016), so auch die des Grillenburger Sandsteins (Abb. 13). Auch verjüngt sich der Durchmesser der Gänge bei marinen Spurenfossilien nie: er ist immer genauso groß, wie der Umfang des Erzeugers!

Auf der teilweise welligen, im Allgemeinen aber planaren Oberfläche des Werksandsteins mit einigen Kolken
(Abb. 12a, b) beginnt nach einer Schichtlücke die Pennrich-Formation (oberes Obercenomanium; ehemalige sandige Dölzschen-Formation, siehe Niebuhr 2020) mit einem 25-80 $\mathrm{cm}$ mächtigen Transgressionskonglomerat (basaler Abschnitt 2 auf Abb. 12a, b). Die größeren Komponenten bestehen ausschließlich aus sehr gut gerundeten Rhyolith-Geröllen, die in einer grobsandigen Matrix mit vielen Bioklasten und idiomorphen Quarzdihexaedern schwimmen (Probe FJ 3 auf Abb. 12f). Die Gerölle, die einerseits stark kaolinisiert, aber teilweise auch sehr frisch sind (Abb. 12c, m), können einen Durchmesser von $15 \mathrm{~cm}$ erreichen und entstammen - wie auch die idiomorphen Quarzdihexaeder - dem phenokristallreichen Rhyolith („quarzreichen Porphyr") und phenokristallarmen Rhyolith in Ignimbrit-artiger Entwicklung (,quarzarmen Porphyr") der permischen Tharandter-Wald-Caldera.

An marinen Fossilien - teils verkieselt, meist als Lösungshohlräume - wurden aus dem Transgressionskonglomerat an der Basis der Pennrich-Formation Austern (Rastellum carinatum, Rhynchostreon suborbiculatum), Pectiniden (Neithea aequicostata) und Spondyliden (Spondylus hystrix) bestimmt, wobei die häufigen R. carinatum als Epibionten auch direkt den Rhyolith-Geröllen aufgewachsen gefunden wurden (Sauer 1887; Häntzschel 1933; Probe FJ 4 auf Abb. 12m).

Im alten Steinbruch Nr. 92 werden in der dort ca. $80 \mathrm{~cm}$ mächtigen, massiven Bank (Abb. 12b) die größten Gerölle gefunden. Im heutigen Steinbruch Nr. 104 geht die grobsandige Matrix des basalen Konglomerats ins Hangende nach ca. $25 \mathrm{~cm}$, unter allmählichem Ausfall der wesentlich kleineren Rhyolith-Gerölle, in einen ca. $80 \mathrm{~cm}$ mächtigen glaukonitisch-bioklastischen Mittelsandstein mit großen, isolierten Quarzkörnern über (mittlerer Abschnitt 2 auf Abb. 12a; Probe JF 5). Die kleinwüchsige Muschelfauna dieser gelblich-rosa gefleckten, stark tonigen Schicht, die dem plenus-Horizont entspricht (vgl. Niebuhr 2020), übersteigt wenige Millimeter nicht. Die obersten ca. $50 \mathrm{~cm}$ des Abschnitts 2 bestehen aus bioturbaten, knolligen und stärker verfestigten, glaukonitischen Fein- bis Mittelsandsteinen mit vielen verkieselten 
Bioklasten und Holzresten. Ockergelbe, stark poröse Partien (Probe JF 7 auf Abb. 12g) weisen einen hohen Anteil von Lösungshohlräumen oder Verkieselungen ehemaliger karbonatischer Bioklasten auf (Muschel- und Brachiopodenschalen, über $3 \mathrm{~cm}$ lange, kräftig geriefte Stacheln des regulären Seeigels Phalacrocidaris vesiculosa); weiße, tonige Feinsandsteine, wie sie beispielsweise als Füllung der Spurenfossilien in der Probe JF 8 erscheinen (Abb. $12 \mathrm{k}$ ), sind frei von ehemals karbonatischen Bioklasten resp. ihren Lösungshohlräume.

Den Abschluss bilden mit einem deutlichen lithologischen Schnitt sogenannte Plänersandsteine (Abschnitt 3 auf Abb. 12a): weiß-gelblich gefleckte, spiculitisch-glaukonitische Siltsteine mit viel Hellglimmer. Von ihnen sind im heutigen Steinbruch Nr. 104 noch ca. 3 m erhalten, im alten Steinbruch Nr. 92 sind es bis zu $7 \mathrm{~m}$. Der untere Abschnitt ist sehr gut gebankt mit Schichtmächtigkeiten (vom Liegenden ins Hangende) von $26 \mathrm{~cm}, 40 \mathrm{~cm}, 40 \mathrm{~cm}$, $40 \mathrm{~cm}$ und $22 \mathrm{~cm}$ (Proben FJ 10-13), der obere Abschnitt darüber ist plattig ausgebildet (Proben FJ 14-16). Die sehr feinkörnigen Gesteine sind stark verkieselt, die losen Kieselknollen durch dünne, limonitische Häutchen begrenzt (Proben FJ 10, 11). Einige Bänke enden am Top mit einer Muschelschilllage (Probe FJ 13). Die Siltsteine sind fossilarm, die auftretenden Hohlräume der Muschelschille eher klein (Abb. 12h). Einige Lagen sind so reich an großen monaxonen Megaskleren von Kieselschwämmen, dass sie als Spiculite bezeichnet werden können (z. B. Proben FJ 10, 13 auf Abb. 12j). Häntzschel (1933) fand in den Plänersandsteinen die sogenannte „Pennricher Fauna" mit verschiedenen Austern, Spondyliden, Serpuliden und den bis zu $2 \mathrm{~cm}$ langen, keulenförmigen Stacheln des regulären Seeigels Tylocidaris sorigneti.

\section{Interpretation und Korrelation der Kreidesandstein-Lokalitäten}

(1) Am Hartheberg tritt die ca. $20 \mathrm{~m}$ mächtige mittlere und obere Oberhäslich-Formation mit ein oder zwei „Exogyrenbänken“ (ca. 375-395 m ü. NHN, Mittel- und unteres Obercenomanium nach Wilmsen et al. 2022) im Hangenden einer ca. $17 \mathrm{~m}$ mächtigen fluviatilen, unteren und mittleren Niederschöna-Formation auf (ca. 358375 m ü. NHN, Untercenomanium). Im Steinbruch am Nord-Hang (Nr. 119 bei Eberlein 2004) sind die untersten Meter der mittleren Oberhäslich-Formation mit der basalen „Exogyrenbank“ zwischen 375-378 m ü. NHN aufgeschlossen (Schreiter 1927: S. 94). Der Steinbruch wurde jedoch nicht wegen des Werksandsteins angelegt, sondern geht auf die erfolglose „Schürfung auf Kohle“ zurück (Sauer 1891: S. 69).

Die beste Profilbeschreibung des Steinbruchs Nr. 121 am Südost-Hang lieferte Schreiter (1927: S. 93): „Der Weg biegt in eine ostwestlich verlaufende Richtung um, und wir befinden uns am Fuße der jäh abstürzenden, bis zu 20 m hohen Bruchwände. Das Massiv des Hartheber- ges wird in seinem unteren Sockel aus unterem Quadersandstein mit Pecten asper, Ostrea carinata, Exogyra columba, Serpula u.a. gebildet, dem nach oben Plänersandstein mit Cidaris Sorigneti u.a. auflagert.“ Hier liegt eine „Exogyrenbank“ in der mittleren Oberhäslich-Formation auf ca. $380 \mathrm{~m}$ ü. NHN (Sauer 1891; Schreiter 1927), ist aber heute überschüttet. Im Hangenden des Werksandsteins liegen im Steinbruch Nr. 121 zu unterst der ca. $2 \mathrm{~m}$ mächtige, feinkörnige und weitgehend unverfestigte plenus-Horizont (,Pennricher Sandstein mit Löcherhorizont"; siehe Profil bei Martick 1999; Eberlein 2004: Abb. 5.49) mit der charakteristischen „Pennricher Fauna“ (Häntzschel 1933), bevor bei ca. 397 m ü. NHN die fossilarmen Plänersandsteine der Pennrich-Formation einsetzen, die weiter hinauf bis auf den Gipfel des Hartheberges bei 405,50 m ü. NHN (als sandige Dölzschen-Formation) nachgewiesen wurden (Alexowsky et al. 2012).

(2)-(4): Im zusammengesetzten Profil in und bei Grillenburg (Bohrung Gug 1308/1962, Brunnen der alten Grillenburger Schule, Sandsteinbruch am Flügel Jägerhorn, Bohrung HtzFr 1307/1962) ist die mittlere und obere Oberhäslich-Formation (Mittel- und unteres Obercenomanium nach Wilmsen et al. 2022) rund $22 \mathrm{~m}$ mächtig (zwischen 370-395 m ü. NHN, unter Abzug des leichten Einfallens nach Südosten). In der Bohrung Gug 1308/1962 (Tröger in Alexowsky et al. 2012: S. 170) liegt die mittlere Oberhäslich-Formation mit einem dünnen, polymikten Basalkonglomerat auf der ca. $7 \mathrm{~m}$ mächtigen fluviatilen, mittleren Niederschöna-Formation (ca. 363$370 \mathrm{~m}$ ü. NHN, Untercenomanium) und in der Bohrung HtzFr 1307/1962 (Interpretation B.N., diese Arbeit) befindet sich zwischen 378-382 m ü. NHN an der Basis der Oberhäslich-Formation ein quarzdominiertes Transgressionskonglomerat mit Rhyolith-Geröllen direkt auf dem Rhyolith der Tharandter-Wald-Caldera. Die Dachfläche des Werksandsteins (Sequenzgrenze SB Ce 5) ist entweder planar oder wellig ausgebildet (Abb. 12a, b). Die Pennrich-Formation oberhalb von $395 \mathrm{~m}$ ü. NHN (oberes Obercenomanium) beginnt im Sandsteinbruch am Flügel Jägerhorn ebenfalls mit einem Transgressionshorizont aus Rhyolith-Geröllen im basalen plenus-Horizont, gefolgt von gut gebankten Siltsteinen (Plänersandsteinen) mit typischer „Pennricher Fauna“, von denen sich noch 3-7 $\mathrm{m}$ im Steinbruch am Flügel Jägerhorn erhalten haben; in der Bohrung HtzFr 1307/1962 ist die Pennrich-Formation noch ca. 9 m mächtig (394-403 m ü. NHN). Die Mächtigkeit des Rhyolith-Konglomerats oberhalb der Sequenzgrenze SB Ce 5 nimmt auf kurze Distanzen vom östlichen Steinbruch-Ausgang am Flügel Jägerhorn nach Westen im alten Steinbruch Nr. 92 von ca. $25 \mathrm{~cm}$ bis auf ca. $80 \mathrm{~cm} \mathrm{zu}$.

(5) Im alten Quaderbruch im Forstrevier 8, der heute fast vollständig überwachsen ist, wurden ursprünglich die obersten $3 \mathrm{~m}$ (ca. 408-411 m ü. NHN) der oberen Oberhäslich-Formation abgebaut (Sauer 1887), die etwa in der Mitte des Werksandsteins eine dünne „Exogyrenbank“ enthält. Im Liegenden der Steinbruch-Basis wur- 
den am Nordhang des Rodelandbachs zwischen $408 \mathrm{~m}$ und ca. $390 \mathrm{~m}$ ü. NHN in der geologischen Karte zahlreiche Funde von „Exogyrenbänken“ verzeichnet (Sauer 1899). Somit können erst die Schichten unterhalb von ca. 390 m ü. NHN zur fluviatilen, mittleren NiederschönaFormation (Untercenomanium) gerechnet werden. Ein Aufschluss zwischen der Steinbruch-Basis und dem tiefer gelegenem Rodelandbach ist nicht vorhanden. Die ca. $4 \mathrm{~m}$ mächtige Steilstufe, die ,unmittelbar dem Steinbruch vorsteht“, gehört ebenfalls zum Werksandstein (mit „Exogyrenbänken“) und nicht als „Dünensandstein“ zur Niederschöna-Formation (cf. Göhler 2011). Die damit ca. $21 \mathrm{~m}$ mächtige mittlere und obere Oberhäslich-Formation (Mittel- und unteres Obercenomanium nach Wilmsen et al. 2022) transgrediert entweder direkt auf den Rhyolith der Tharander-Wald-Caldera oder auf die fluviatile, untere und mittlere Niederschöna-Formation (Untercenomanium), die nach Westen, in Richtung Niederschöna, bis 25 m mächtig wird (cf. Sauer 1899).

Die Pennrich-Formation oberhalb von ca. $411 \mathrm{~m}$ ü. NHN (oberes Obercenomanium) beginnt oberhalb der Sequenzgrenze SB Ce 5 mit dem feinkörnigen plenus-Horizont, einem losen Sand mit vielen verkieselten, unverfüllten Brachiopoden-Gehäusen, in denen teilweise noch das Armgerüst erkennbar ist (Horn 1938), gefolgt von gut gebankten Plänersandsteinen, von denen höchstens noch ca. $2 \mathrm{~m}$ im Steinbruch erhalten sind. Auch sie führen die typische „Pennricher Fauna“ (Sauer 1887; Göhler 2011). Ein Foto der Oberhäslich-/Pennrich-Formationsgrenze (Sequenzgrenze SB Ce 5) mit der welligen Dachfläche des Werksandsteins liefert Göhler (2011: Abb. 3).

\section{Korrelation}

Die Kreidesandstein-Profile auf der Tharandter-Wald-Caldera zeigen viele Gemeinsamkeiten. Die durchschnittlichen Mächtigkeiten der mittleren und oberen Oberhäslich-Formation zusammen, aufliegend auf der mittleren Niederschöna-Formation und überlagert durch die Pennrich-Formation, liegen bei etwa $20 \mathrm{~m}$ (Hartheberg: 20 m - Grillenburg: $22 \mathrm{~m}$ - alter Quaderbruch: $21 \mathrm{~m}$ ). Dies steht im Gegensatz zu einer angenommenen Mächtigkeit von nur ca. $10 \mathrm{~m}$ für die Oberhäslich-Formation auf den geologischen Karten 5046 Freiberg und 5047 Freital (geologische Karte und Tröger in Alexowsky et al. 2012: S. 79). Am Hartheberg legt ein Vergleich des neuen Kartierbefundes (Alexowsky et al. 2012) mit den Profilaufnahmen im südöstlichen Steinbruch Nr. 121 (Schreiter 1927; Martick 1999; Eberlein 2004) die Möglichkeit nahe, dass die ca. $10 \mathrm{~m}$ mächtige Kartiereinheit ,,spKc ${ }^{3} D$ ölzP, Dölzschen-Formation, Pennricher Sandstein, lokal mit basalem plenus-Ton" sicher nicht ausschließlich die heutige Pennrich-Formation umfasst, sondern auch Teile des Werksandsteins der oberen Oberhäslich-Formation. Ähnliches gilt auch für den alten Quaderbruch: der $3 \mathrm{~m}$ mächtige, massige Werksandstein der oberen Oberhäslich-Formation, der dort abgebaut wurde, weist bei geländemorphologischer Betrachtung im GIS eine Deckungsgleichheit mit der Pennrich-Formation auf. Die
„Serpulasande“ resp. der „Pennricher Sandstein“ älterer geologischer Karten und Publikationen, die dem massigen Werksandstein aufliegen und von den ausgeprägt gebankten Plänersandsteinen überlagert werden, entsprechen heute dem feinkörnigen plenus-Horizont - benannt nach dem für einen sehr kurzen Zeitabschnitt eingewanderten Belemniten Praeactinocamax plenus (Niebuhr 2021: S. 57, 106, 148). In den Profilen auf dem Osterzgebirge konnte lediglich eine maximale Mächtigkeit von 2 $\mathrm{m}$ beobachtet werden (cf. Janetschke und Wilmsen 2014). Als wichtiges Unterscheidungsmerkmal für die Grenzziehung zwischen der Oberhäslich- und Pennrich-Formation kann das Auftreten von Glaukonit gelten, welches charakteristisch für alle Untereinheiten der Pennrich-Formation gelten kann (plenus-Horizont, Serpulasande, Plänersandsteine), in der Oberhäslich-Formation jedoch entweder gar nicht oder - so auch im alten Steinbruch Nr. 92 am Flügel Jägerhorn - ausgesprochen selten als wasserhelle, gelbgrünliche Variante vorkommt (cf. Wilmsen und Bansal 2021).

Die Oberhäslich-Formation auf dem Osterzgebirge zeigt in allen Profilen eine deutliche Zweiteilung (siehe z. B. Profil Sandberg in der Paulsdorfer Heide, Abb. 1; cf. Janetschke und Wilmsen 2014; Janetschke et al. 2015): die untere Hälfte (Merbitz-Member des Mittelcenomaniums nach Wilmsen et al. 2022) ist lithologisch wechselhaft, fein- bis grobkörnig, mit häufigen Konglomerat-Lagen und Austernbänken, oftmals schräggeschichtet; die obere Hälfte hingegen (Werksandstein-Member des unteren Obercenomaniums) meist fein- bis mittelkörnig, sehr gut sortiert, dickbankig bis massig und fossilarm - die beste Werksandstein-Qualität. Pietzsch (1914: S. 103) bemerkt dazu: „Die festeren, überdies durch gleichmäBigeres Korn ausgezeichneten Bänke liegen vorwiegend in der oberen Abteilung des Carinatenquaders, weshalb diese auch am häufigsten durch Steinbrüche aufgeschlossen sind.“ Dies wird auch durch die petrographisch-gesteinstechnische Charakterisierung und Vergleiche von Sachsens Bausandsteinen bestätigt (Siedel et al. 2011): die Ähnlichkeiten zwischen der ,Werksteinbank des Steinbruchs Horkenberg bei Bannewitz“ (Häntzschel 1933: S. 39, 40; Janetschke und Wilmsen 2014) und dem „Grillenburger Sandstein aus der Werksteinbank des Steinbruchs Grillenburg" sind bis auf eine etwas geringere Porosität (etwa $19 \%$ versus $25 \%$ ) und damit stärkere kieselige Zementierung am Horkenberg unübersehbar.

Als einziger cenomanzeitlicher Werksandstein der sächsischen Kreide wurden in den Sandsteinbrüchen des Osterzgebirges jeweils die obersten 5-7 m der Oberhäslich-Formation abgebaut (Abb. 1, 4a). Die Dachfläche ist in den Lokalitäten auffällig ähnlich ausgebildet (vgl. Abb. 12a = alter Steinbruch Nr. 92 am Flügel Jägerhorn mit Göhler 2011: Abb. 3 = alter Quaderbruch). Der Werksandstein der oberen Oberhäslich-Formation bildet eine auffällige, morphologische Steilstufe im Gelände, dem der Steinbruch-Betrieb folgte, besonders gut westlich und östlich des alten Quaderbruchs am Nordhang des Rodelandbaches zu sehen. 
Die genannte stratigraphische Einstufung gilt auch für weitere „Dünensandsteine“ von Häntzschel (1933, 1934) und Prescher (1957: S. 53) auf dem Kartenblatt 5047 Freital: den „höchsten Lagen im Stbr. Schneise 9" südwestlich des Ascherhübels (oberhalb von ca. 365 m ü. NHN; Nr. 106 bei Eberlein 2004), dem „Steilhang am Porphyrweg“" westlich des Ascherhübels (oberhalb von ca. $380 \mathrm{~m}$ ü. NHN; Nr. 105 bei Eberlein 2004), dem „Steilhang des Börschels-Bergs“/Borschelsberges (oberhalb von ca. $375 \mathrm{~m}$ ü. NHN); und dem „Gipfel des Markgrafensteins“" (oberhalb von ca. 400 m ü. NHN; Nr. 110 bei Eberlein 2004). Die Schichten am Ascherhübel (Nr. 105, 106), auch die des Steinbruchs an der Ost-Seite (oberhalb von ca. $385 \mathrm{~m}$ ü. NHN; Nr. 107 bei Eberlein 2004) und auf dem Gipfel des Markgrafensteins (Nr. 110) wurden bereits als marine Oberhäslich-Formation kenntlich gemacht (Martick 1999; Eberlein 2004).

„Exogyrenbänke“ scheint es in der mittleren und oberen Oberhäslich-Formation des Tharandter Waldes offenbar mehrere auf unterschiedlichen Niveaus zu geben. Häufig sind sie im unteren Abschnitt anzutreffen, im Werksandstein sind sie selten. Im alten Quaderbruch im Forstrevier 8 wurde die höchste Austernbank nur 1,50$2 \mathrm{~m}$ unterhalb der Werksandstein-Dachfläche bei ca. 409 m ü. NHN nachgewiesen, weitere Funde wurden am darunter liegenden Nordhang des Rodelandbaches bis auf ca. 390 m ü. NHN kartiert (Sauer 1886, 1887). Bei Spechtshausen existiert am Hartheberg eine basale „Exogyrenbank" am Nord-Hang (375-380 m ü. NHN) und eine am SO-Hang auf ca. $380 \mathrm{~m}$ ü. NHN (Sauer 1889, 1891; Schreiter 1927). Ob es sich dabei um Dieselbe handelt, ist unklar. Zusätzlich ist bei Tröger (1969: Anl. 4) eine weitere „Exogyrenbank“ etwa 6 m unterhalb der Werksandstein-Dachfläche bei $389 \mathrm{~m}$ ü. NHN angegeben. In der mittleren Oberhäslich-Formation bei Grillenburg (Bohrungen Gug 1308/1962 und HtzFr 1307/1962) ist keine „Exogyrenbank“ verzeichnet. Ob zusammengeschwemmte Muschelschille zur Korrelation der einzelnen Profile herangezogen werden können (cf. Sauer 1891; Schreiter 1927), erscheint unsicher.

Die Pennrich-Formation des oberen Obercenomaniums wird in ihrer Typusregion, dem Osterzgebirge, im Allgemeinen 6-8 m mächtig, in Einzelfällen liegt die maximale Mächtigkeit bei 12-15 m (Janetschke und Wilmsen 2014; Niebuhr 2020; Wilmsen und Bansal 2021). Dies wiederum unterschreitet deutlich die Mächtigkeit von 20-30 m, die (als sandige Dölzschen-Formation) für Blatt 5047 Freital angegeben wird (geologische Karte und Tröger in Alexowsky et al. 2012: S. 84). Auch hier deutet einiges auf eine unterschiedliche Handhabung bei der Abgrenzung der Oberhäslich- von der Pennrich-Formation. Neben dem zum Teil sehr hohen Glaukonit-Gehalt der Pennrich-Formation (Wilmsen und Bansal 2021) ist im unteren Abschnitt die „Pennricher Fauna“ typisch, allerdings bestehen hinsichtlich der quantitativen Zusammensetzung des Faunenbildes starke Unterschiede (Tröger 1969; Föhlisch 1998). Es treten beispielsweise verschiedene Austern (Rhynchostreon suborbiculatum, Rastellum carinatum, $R$. diluvianum), Inoceramen (Inoceramus pic- tus bannewitzensis), Spondyliden (Spondylus hystrix, $S$. latus) und weitere Muscheln auf, z. B. Neithea aequicostata und Entolium membranaceum. Weiterhin wurden die Solitär-Koralle Micrabacia coronula, Kieselschwämme wie z. B. Plocoscyphia pertusa, angebohrte Brachiopodenschalen von Neoliothyrina phaseolina, die bis zu $20 \mathrm{~mm}$ langen, keulenförmigen Stacheln des regulären Seeigels Tylocidaris sorigneti und besonders die Sabellide (früher: Serpulide) Glomerula lombricus gefunden, die dem „Serpulasand“ im Liegenden der Plänersandsteine wegen ihres dortigen Massenvorkommens seinen Namen gab (Sauer 1887; Pietzsch 1914; Häntzschel 1933; Horn 1938; Tröger 1969; Göhler 2011; Niebuhr 2021). Im Gegensatz zur Oberhäslich-Formation, in der die Fossilien generell als Abdrücke oder Steinkerne im Sandstein erhalten sind (siehe Abb. 7, 8 rechts), wurden die ursprünglich karbonatischen Bestandteile der „Pennricher Fauna" im plenus-Horizont und den Plänersandsteinen oftmals sekundär silifiziert (siehe Horn 1938: Abb. 11; Göhler 2011: Abb. 7; Abb. 12m; Niebuhr 2021: S. 131, 149).

In der Bohrung HtzFr 1307/1962 liegen die mittlere und obere Oberhäslich-Formation direkt auf dem Rhyolith der Tharandter-Wald-Caldera, der bei Grillenburg eine Brandungsklippe an einer bis nach Pohrsdorf reichenden Insel bildete (Tröger 1969). Auch die Plänersandsteine der Pennrich-Formation transgredieren nur ca. $500 \mathrm{~m}$ nordwestlich und westlich des Sandsteinbruchs am Flügel Jägerhorn bei einem weiteren Meeresspiegelanstieg im oberen Obercenomanium direkt auf den Rhyolith (z. B. Bohrungen HtzFr 637/1969 und HtzFr 595/1969; Abb. 4) - dort ist das Herkunftsgebiet der Rhyolith-Gerölle auf der Dachfläche des Werksandsteins im Sandsteinbruch am Flügel Jägerhorn zu suchen. Abgebaut wurde am Flügel Jägerhorn, wie in allen größeren Sandsteinbrüchen, nur die beste Werksandstein-Qualität der oberen 5-7 m. Die bei Henckel (1722) abgebildeten Muscheln kommen sicherlich aus dem heute aufgeschütteten Bereich unterhalb der Steinbruch-Basis im alten Steinbruch Nr. 92, da in dem heute anstehenden Werksandstein bisher keine (Körper-)Fossilien gefunden wurden.

Die gesamte lithologische Abfolge in Grillenburg beschreibt eine mittel- bis obercenomane Brandungsklippe, wie sie bereits aus anderen sächsischen Lokalitäten bekannt ist; so etwa auch im berühmten Steinbruch an der Heidenschanze in Dresden-Coschütz (Voigt T. et al. 1994; Walter und Suhr 1997; Voigt S. et al. 2006; Janetschke und Wilmsen 2014): die Basis der mittleren und oberen Oberhäslich-Formation bildet eine ca. $5 \mathrm{~m}$ mächtige Abfolge von proximalen Tempestiten mit massenhaft Muschel- und Schneckenschill („Muschelfelsen von Koschütz", mittelcenomanes Merbitz-Member nach Wilmsen et al. 2022), auf den darüber liegenden, ebenfalls ca. $5 \mathrm{~m}$ mächtigen Werksandstein folgen mit einer Schichtlücke (= SB Ce 5) kalkig zementierte, grobe Konglomerate der Dölzschen-Formation, die im Hangenden abrupt von mergeligen Siltsteinen, den plenus-Plänern, überlagert werden. 


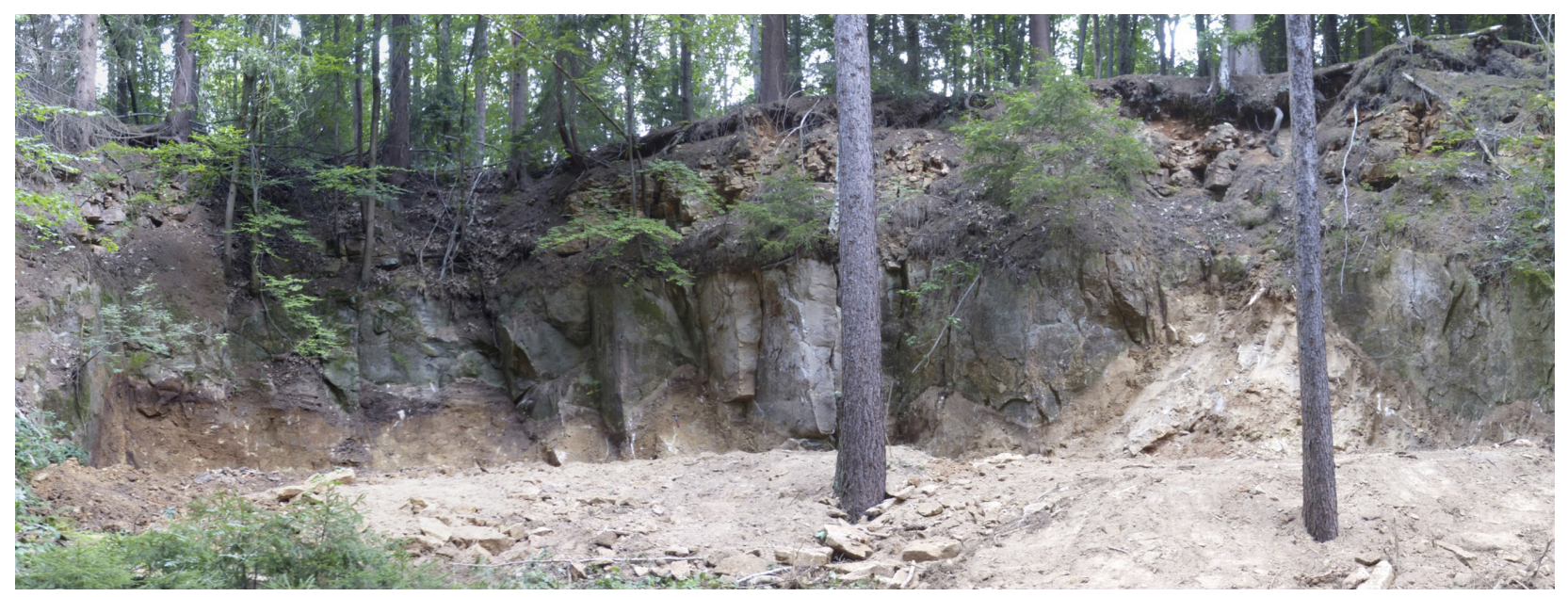

Abbildung 14. Die ca. 10 m hohe Nordwand des heutigen Sandsteinbruchs Nr. 104 im Sommer 2020 (Foto: F. Haubrich 2020). Der Werksandstein der oberen Oberhäslich-Formation im unteren Abschnitt ist über eine Länge von ca. 40 m komplett freigeräumt worden. Die hangenden spiculitischen Siltsteine der Pennrich-Formation sind gut sichtbar, aber nicht gefahrlos zu erreichen.

Figure 14. The ca. 10-m-high northern wall of the current sandstone quarry no. 92 in summer 2020 (photo: F. Haubrich 2020). The sandy freestone of the upper Oberhäslich Formation in the lower part has been completely exposed over a length of approximately $40 \mathrm{~m}$. The overlying spiculitic siltstones of the Pennrich Formation are clearly visible, but not safely accessible.

\section{Geotop-Schutz: Aktivitäten und Ausblick}

In dem flammenden Plädoyer für die Erhaltung von „Erdgeschichtlichen Natururkunden aus dem Sachsenlande“" (Wagner 1930) war der Sandsteinbruch am Flügel Jägerhorn noch nicht aufgeführt. Doch noch vor Einstellung des Steinbruchbetriebs wird er auf Intervention von Paul Wagner als damaligen Leiter des Landesvereins Sächsischer Heimatschutz, Dresden, von der Vorgängerinstitution der heutigen Unteren Naturschutzbehörde des Landratsamts Freital als Naturdenkmal „Sandsteinbruch“ anerkannt. Die entsprechende Tafel mit dem Zitat ,Werksteinbank, wurde noch abgebaut" (Abb. 15, oben rechts) stand noch 2004 am Eingang zum Steinbruch (Eberlein 2004). Der heutige Grillenburger Sandsteinbruch Nr. 104, Geotop Nr. 559 des Geotopkatasters Sachsen, steht seit dem 25. Mai 1978 als Flächennaturdenkmal (FND) WRK 033 unter Schutz - als eines von vier geologischen FND des Landschaftsschutzgebiets Tharandter Wald und einziger Kreidesandstein-Aufschluss (Umweltportal Sachsen 2020; Grüne Liga Osterzgebirge 2021a). Mit demselben Vorgang wurde damals auch das unmittelbar südlich angrenzende, auf der alten Steinbruchhalde gelegene Biotop mit einer Buchen-Traubeneichen-Restbestockung als FND WRK 032 geschützt (Umweltportal Sachsen 2020; Grüne Liga Osterzgebirge 2021b; Lage siehe Abb. 15). In den Jahren nach der Einstellung des Abbaubetriebs Ende der 1940er Jahre verfiel der Steinbruch zusehends. In einem veröffentlichten Exkursionsführer von Beeger und Quellmalz (1965) wird er vermutlich letztmalig aufgeführt, und auch die Studierenden der Geowissenschaften der TU Bergakademie Freiberg besuchten ihn aufgrund der schlechten Aufschlussverhältnisse in den letzten Jahren nicht mehr (B. Gaitzsch, schriftl. Mitt. 05/2021).
Im April 2020 wurde zusammen mit der Leitung des Vereins GeoPark Sachsens Mitte, dem Staatsbetrieb Sachsenforst als Eigentümer und der Naturschutzbehörde beratschlagt, ob und wie der Sandsteinbruch am Flügel Jägerhorn wieder begehbar gemacht werden kann, um die anstehenden Kreidesandsteine der Bevölkerung und den Geowissenschaftlern wieder nahebringen zu können. Dabei wurde festgestellt, dass der zentrale Bereich des Sandsteinbruchs Nr. 104 weitgehend versumpft ist und eine moosartige Vegetation mit einer dominierenden Ohrweiden-Population aufweist (Grüne Liga Osterzgebirge 2011). Da es Konsens war, Biologie und Geologie gleichermaßen zu betrachten, existiert somit im zentralen Bereich ein Feuchtbiotop und im hinteren, westlichen Bereich des ehemaligen Steinbruchbetriebs das Geotop Nr. 559 (Abb. 15). Im Sommer 2020 wurde der heutige Sandsteinbruch Nr. 104 durch den Staatsbetrieb Sachsenforst und Mitgliedern des GeoPark-Vereins von umgestürzten Bäumen und Wildwuchs freigeräumt mit dem Hintergrund, den Zustand so zu gestalten, dass er zukünftig als zentrales Kreidesandstein-Geotop des GeoParks Sachsens Mitte geführt werden könnte (Weber 2020). Der Zustand der nordwestlichen Bruchwand im hintersten Bereich, die ursprünglich als Geotop ausgewiesen wurde, wurde zum großen Teil wieder hergestellt. Der Werksandstein ist über eine Länge von ca. $40 \mathrm{~m}$ komplett freigeräumt worden und die Plänersandsteine der Pennrich-Formation sind im oberen Bereich gut sichtbar, wenn auch nicht gefahrlos zu erreichen (Abb. 14).

Im August 2020 wurde das gesamte Grillenburger Steinbruchgebiet ausgiebig von Mitgliedern des Fördervereins Geologie im Tharandter Wald begutachtet. Dabei wurde festgestellt, dass in dem alten, südwestlich vorgelagerten Abbaubereich Nr. 92 die Plänersandsteine der Pennrich-Formation bereits teilweise abgeräumt wurden und somit das $80 \mathrm{~cm}$ mächtige Rhyolith-Konglomerat sowie die Dachfläche des Werksandsteins auf einer Flä- 


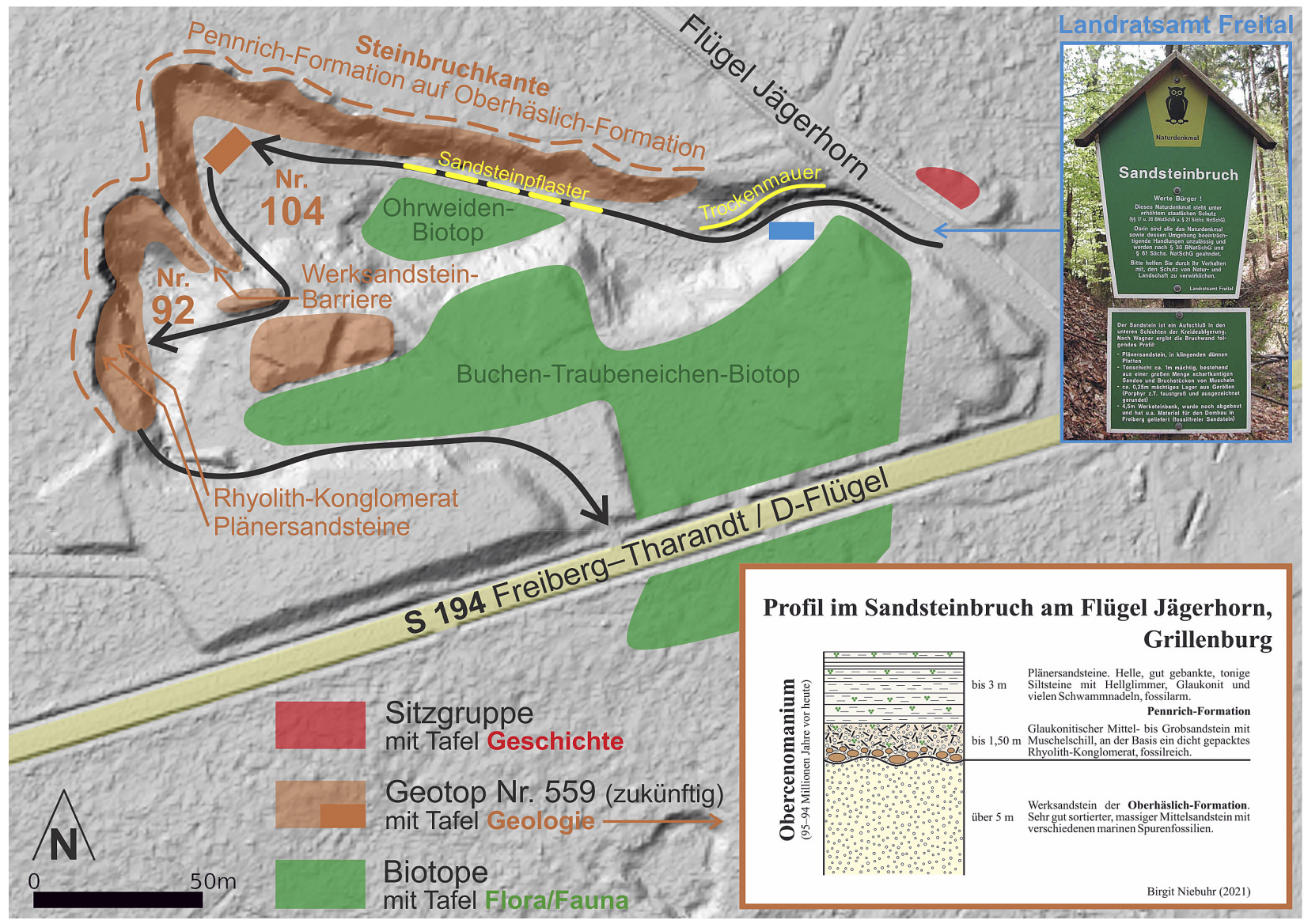

Abbildung 15. Digitales Geländemodell (DGM; GeoSN 2021) des ehemaligen und heutigen Grillenburger Sandsteinbruchs am Flügel Jägerhorn (Geotop Nr. 559). Zur bisherigen Verbreitung der Flächennaturdenkmale WRK 032 und 033 siehe Umweltportal Sachsen (2020).

Figure 15. Digital elevation model (DEM; GeoSN 2021) of the former and recent Grillenburg sandstone quarry at the Flügel Jägerhorn (geotope no. 559). For areal distribution of the previous area national monuments WRK 032 and 033, see Umweltportal Sachsen (2020).

che von $30 \times 10 \mathrm{~m}$ nahezu frei liegen (Abb. 4, 15). Erste Überprüfungen ergaben, dass der Werksandstein - wie in allen Quadersteinbrüchen üblich - selbst nahe an der Bodenoberfläche nur geringfügig verwittert vorliegt und eine sehr gute Festigkeit aufweist. Der besonders für Kreide-Paläontologen interessante Profilabschnitt des Steinbruchs im Hangenden (Pennrich-Formation) ist nur hier gefahrlos zugängig. Daher ist es wünschenswert, den alten Sandsteinbruch Nr. 92 in den FND-Schutz des heutigen Sandsteinbruchs Nr. 104 (Geotop Nr. 559 des Geotopkatasters Sachsen) einzubeziehen, zumal das Material für die historischen Gebäude des 12. bis 16. Jahrhunderts - beispielsweise der Goldenen Pforte - sicher aus diesem Bereich stammt. Dafür wäre auch die Schaffung eines leicht begehbaren Überganges zwischen dem heutigen und alten Abbaugebiet nötig (Vorschlag: schwarze Linie in Abb. 15). Im Anschluss würden Geowissenschaftler, Studierende und interessierte Laien gleichermaßen in diesem Steinbruch hervorragende Aufschlussmöglichkeiten für eine Besichtigung vorfinden, um neue Erkenntnisse über die Sedimentation der sächsischen Kreide zu gewinnen - weil eben nicht ein Dünensandstein, sondern ein flachmariner Quadersandstein aus dem unteren Obercenomanium hier 770 Jahre lang abgebaut wurde.

\section{Tabellarische Kurzfassung}

- Der Steinbruch am Flügel Jägerhorn westlich von Grillenburg ist vermutlich der älteste Kreidesandsteinbruch des Tharandter Waldes, mit Unterbrechungen in Betrieb seit etwa 1170, wie Werkstücke aus dem Lapidarium der Klosterkirche in Altzella belegen (Beeger in Grunert 1986).

- Aus Grillenburger Sandstein wurden beispielsweise Anfang des 13. Jahrhunderts die Goldene Pforte des Freiberger St.-Marien-Doms und das an der Westseite der Stadtkirche in Nossen befindlichen Portal, das ursprünglich aus dem Kloster Altzella stammt, gefertigt. Weiterhin wurde er bis ins 16. Jahrhundert hinein zum „schnellen Aufbau Freibergs zur damals größten Stadt Sachsens" verwandt (Bachmann 1936). Von Beginn des 19. Jahrhunderts bis zur Einstellung des Steinbruchbetriebs etwa 1940 wurden vorzugsweise Schleifsteine für Holzschleifereien hergestellt. Das vermutlich letzte Gebäude, für das der Werksandstein aus dem Steinbruch am Flügel Jägerhorn zum Einsatz kam, ist das Gästehaus Neues Jägerhaus in Grillenburg, erbaut 1938-1939. 
- Henckel (1722) veröffentlichte aus dem „Sandsteinbruche im Grüllenburger Walde" die bisher ältesten bekannten Abbildungen von sächsischen Kreide-Fossilien: die Hahnenkamm-Muschel Rastellum carinatum und die Pectinide Merklinia aspera.

- Obwohl damit bereits vor 300 Jahren beide „Leitmuscheln“ der früheren „Oberen Stufe des unteren Quadersandsteins mit dem Pecten asper und der Ostrea carinata" nachgewiesen waren, wurde die Grillenburger „Werksteinbank“ fälschlicherweise in den letzten über 130 Jahren der kontinentalen Niederschöna-Formation zugeordnet und als fossilleerer Dünensandstein interpretiert (Häntzschel 1933, 1934).

- Das Profil im Sandsteinbruch am Flügel Jägerhorn gliedert sich wie folgt: An der Basis liegt der über $5 \mathrm{~m}$ mächtige, massige Werksandstein der oberen Oberhäslich-Formation (unteres Obercenomanium), ein sehr gut sortierter, homogener, mittelkörniger Quarzsandstein. Es folgt mit ca. 1,50 m Mächtigkeit der fossilreiche, mittel- bis grobkörnige plenus-Horizont der Pennrich-Formation (oberes Obercenomanium), der an der Basis ein Transgressionskonglomerat aus Rhyolith-Geröllen von bis zu $15 \mathrm{~cm}$ im Durchmesser aufweist. Er wird überlagert von gut gebankten, spiculitisch-glaukonitischen Siltsteinen (sogenannte Plänersandsteine), von denen noch 3-7 m im Steinbruch erhalten sind.

- Besonders in den obersten 1,50-2 m des Werksandsteins am Flügel Jägerhorn wurden neben selten auftretendem Glaukonit auch fünf verschiedene marine Spurenfossilien gefunden (Ophiomorpha saxonica, Thalassinoides suevicus, ?Palaeophycus tubularis, Taenidium cameroniensis, Skolithos linearis), die mit einfachen, unverzweigten und überwiegend senkrechten Schäften die Skolithos-Ichnofazies des sandig-flachmarinen Ablagerungsraumes mit hoher Wasserenergie oberhalb der Sturmwellenbasis charakterisieren (cf. Seilacher 1967).

- Im Gegensatz zu den dünnen, spitz zulaufenden und hohlen, pflanzlichen Röhren der fluviatilen Wurzelhorizonte bei Niederschöna (Häntzschel 1933, 1934) sind die marinen Spurenfossilien des Grillenburger Werksandsteins immer verfüllt und der Durchmesser der Gänge verjüngt sich nie.

- Die ursprüngliche Transportart der detritischen Quarze der ,Werksteinbank“ (äolisch, fluviatil oder flachmarin, vgl. Prescher 1957; Beeger et al. 1962) lässt sich aufgrund der korrodierten Kornkontakte und der Ausbildung von syntaxialen, sekundären Kristallflächen der ursprünglich abgerollten Körner nicht sicher ermitteln. Petrographisch-gesteinstechnische Vergleiche cenomaner Bausandsteine von der Osterzgebirgsregion (Siedel et al. 2011) bestätigen die außerordentliche Ähnlichkeit des Grillenburger Sandsteins mit anderen Vorkommen des Werksandsteins der oberen Oberhäslich-Formation.

- Der wesentliche Grund für die 130-Jahre-währende fehlerhafte stratigraphische Zuordnung im Steinbruch Flügel Jägerhorn liegt darin begründet, dass das dortige Rhyolith-Konglomerat an der Basis der Pennrich-Formation (,der Plenus-Zone“) als altersgleich mit der dünnen Quarzkonglomeratlage an der Basis der Ober-
häslich-Formation („des marinen Carinaten-Quaders“) im Steinbruch am Forsthaus Niederschöna angesehen wurde (vgl. Sauer 1887; Häntzschel 1933).

- Bei Grillenburg transgredierten sowohl die mittlere Oberhäslich-Formation (zwischen 370-375 m ü. NHN) als auch die Pennrich-Formation (oberhalb von etwa $395 \mathrm{~m}$ ü. NHN) direkt auf den permischen Rhyolith der Tharandter-Wald-Caldera. In Zusammenhang mit einer $1 \mathrm{~km}$ entfernt niedergebrachten Bohrung, die die Basis der mittleren Oberhäslich-Formation bei ca. $370 \mathrm{~m}$ ü. NHN transgressiv auf der fluviatilen, mittleren Niederschöna-Formation (Untercenomanium) erschließt (Tröger in Alexowsky et al. 2012), errechnet sich (unter Berücksichtigung des flachwinkeligen Einfallens der Schichten nach Südosten) für die mittlere und obere Oberhäslich-Formation bei Grillenburg (Mittel- und unteres Obercenomanium nach Wilmsen et al. 2022) eine Gesamtmächtigkeit von etwa $22 \mathrm{~m}$.

- Diese lithostratigraphische Abfolge ist typisch für das Cenomanium auf dem Osterzgebirge und vergleichbar mit umliegenden Lokalitäten identischen Alters (z. B. Hartheberg, alter Quaderbruch im Forstrevier 8), in denen die Oberhäslich-Formation - jeweils zwischen fluviatiler, mittlerer Niederschöna-Formation und Pennrich-Formation - ebenfalls etwa 20 m Mächtigkeit aufweist. Dies ist deutlich mehr als bisher angenommen (ca. 10 m; vgl. Alexowsky et al. 2012).

- Es wird dringend empfohlen, den alten, südwestlich gelegenen Abbaubereich Nr. 92 in den Geotopschutz des heutigen Sandsteinbruchs Nr. 104 (Geotop Nr. 556 des Geotopkatasters Sachsen) zu integrieren, da nur so der Herkunftsort des historischen Grillenburger Werksandsteins auch in der Zukunft bewahrt wird.

Zusammenfassend sprechen folgende Argumente gegen die Interpretation der Grillenburger „Werksteinbank“ am Flügel Jägerhorn als Dünensandstein:

- Dem massigen, homogenen und vollständig bioturbat entschichteten Mittelsandstein fehlen sämtliche Sedimentstrukturen, insbesondere die bei Niederschöna „öfter erwähnte, ausgezeichnet sichtbare starke Diagonalschichtung großen Maßstabs, die eine alte Dünenstruktur noch deutlich erkennen läßt" (cf. Schander 1924).

- Auch pflanzenführende Tonlagen, Wurzelhorizonte und die „Systeme von dünnen Röhren“ dicht-an-dicht stehender pflanzlicher Reste (cf. Häntzschel 1933, 1934) wurden in der „Werksteinbank“- entgegen der Angaben bei Prescher (1957) -nicht nachgewiesen.

- Hingegen treten hell-gelblichgrüner Glaukonit und fünf verschiedene Taxa mariner Spurenfossilien in den obersten 1,50-2 m auf.

- Die „Werksteinbank“ am Flügel Jägerhorn liegt als vermeintlich ,jüngstes Glied der Crednerien-Schichten“ (Häntzschel 1934) ca. 20 m höher (390-395 m ü. NHN) als die Dachfläche der Niederschöna-Formation in Grillenburg (ca. $370 \mathrm{~m}$ ü. NHN, cf. Tröger in Alexowsky et al. 2012) 
- Es ist den Autoren keine Lokalität in der sächsischen Kreide bekannt, in der bei einem fortschreitendem Meeresspiegelanstieg von mehreren 10er Metern die Pennrich-Formation (mit dem plenus-Horizont $=$,Serpulasande“ resp. „Pennricher Sandstein“), unter Ausfall der Oberhäslich-Formation, direkt auf die Niederschöna-Formation transgredieren würde.

- Und zu guter Letzt: unvoreingenommen betrachtet unterscheidet sich der Sandstein der Grillenburger „Werksteinbank“ am Flügel Jägerhorn in nichts von den obersten 5-7 m der oberen Oberhäslich-Formation, wie er in den zahlreichen Steinbrüchen auf dem Osterzgebirge als einziger cenomanzeitlicher Werksandstein der sächsischen Kreide gebrochen wurde und auch in den Bohrungen der Elbezone in identischer Lithologie erscheint.

\section{Danksagungen}

Der Grillenburger Sandsteinbruch am Flügel Jägerhorn hat eine große historische und geologische Bedeutung für das Landschaftsschutzgebiet Tharandter Wald. Wir danken dem Staatsbetrieb Sachsenforst als Eigentümer sowie den vielen ehrenamtlichen Helfern des GeoParks Sachsens Mitte und des Fördervereins Geologie im Tharandter Wald für ihre Unterstützung zur Wiederherstellung des Geotop-Charakters dieses berühmten Steinbruchs. Wir möchten mit dieser Arbeit auch die Initiative von Frank Stockmann und dem Verein GeoPark Sachsens Mitte bei der Zertifizierung zum Nationalen Geopark Deutschlands unterstützen. Weiterhin bedanken wir uns bei Axel Hiller, dem Leiter des Geologischen Archivs der Wismut GmbH in Hartenstein, für die Publikationsgenehmigung der verwendeten Bohrungen bei Grillenburg. Für rege Diskussionen und wertvolle Verbesserungsvorschläge sei Markus Wilmsen, Peter Suhr und Nadine Janetschke, Museum für Mineralogie und Geologie der Senckenberg Naturhistorischen Sammlungen Dresden, sowie Heiner Siedel, Institut für Geotechnik der TU Dresden, gedankt.

\section{Literatur}

Alexowsky W, Berger H-J, Horna F, Jaschke I, Kurze M, Renno A, Stanek K, Schneider JW, Tröger K-A (2012) Geologische Karte des Freistaates Sachsen 1:25.000. Erläuterungen zu Blatt 5047 Freital, 3. Aufl.: 180 S.; Freiberg.

Bachmann W (1936) Grillenburg. Mitteilungen des Landesvereins Sächsischer Heimatschutz 25(5/8): 97-149.

Beck R $(1892,1889)$ Geologische Specialkarte des Königreichs Sachsen. Blatt 83, Section Pirna, Erläuterungen, 1. Aufl.: 120 S.; Leipzig.

Beeger D (1994) Baugesteine des Meißner Domes. Naturstein 49(3): 118-119.

Beeger H-D, Quellmalz W (1965) Geologischer Führer durch die Umgebung von Dresden: 227 S.; Dresden.

Beeger D, Siedel H (2007) Zur Verwendung von Kreidesandstein aus dem Elbtalgebiet in Architektur und Plastik. In: Siedel H, Franzen C, Weise S (Hrsg.), Elbsandstein. Beiträge zur Tagung des Arbeitskreises zur Erhaltung von Kulturgütern aus Stein (ARKUS) 2007 in Dresden, 39-47.

Beeger H-D, Prescher H, Quellmalz W (1962) Geologisch-mineralogische Untersuchungen der Sandsteine und Zemente an der Goldenen
Pforte am Dom zu Freiberg. Jahrbuch des Staatlichen Museums für Mineralogie und Geologie zu Dresden 1962: 69-114.

Chrząstek A (2013) Middle Turonian trace fossils from the Bystrzyca and Długopole sandstones in the Nysa Kłodzka Graben (Sudetes, SW Poland). Geological Quarternerly 2013(3): 443-466. https://doi. org/10.7306/gq.1105

Cotta B (1836) Geognostische Wanderungen 1. Geognostische Beschreibung der Gegend von Tharandt: 64 S.; Dresden.

Eberlein M (2004) Die Geotope des Tharandter Waldes - Inventarisierung und Bewertung. Diplomarbeit, TU Dresden, Institut für Geographie.

Ettingshausen C von (1867) Die Kreideflora von Niederschoena in Sachsen, ein Beitrag zur Kenntnis der ältesten Dicotyledonengewächse. Sitzungsberichte der Königlich-Kaiserlichen Akademie der Wissenschaften in Wien, Mathematisch-Naturwissenschaftliche Classe 55: 235-264.

Fleischer W (1963) Namen und Mundart im Raum Dresden: Toponymie und Dialektologie der Kreise Dresden-Altstadt und Freital zur Sprach- und Siedlungsgeschichte, Teil 2: 271 S.; Berlin.

Föhlisch K (1998) Palökologie der sandig ausgebildeten Dölzschen Formation (Oberes Obercenoman) Sachsens. Abhandlungen des Staatlichen Museums für Mineralogie und Geologie zu Dresden 43/44: 141-149.

Freiesleben JC (1792) Mineralogisch-bergmännische Beobachtungen auf einer Reise durch einen Theil des meißner und erzgebirgischen Kreises, zu Anfange des 1791. Jahres. Bergmännisches Journal 5(2): 122-156, 200-231, 281-324.

GeoSN, Staatsbetrieb Geobasisinformation und Vermessung Sachsen (2021) Digitales Geländemodell DGM1. Datenlizenz Deutschland Namensnennung - Version 2.0. https://www.govdata.de/dl-de/by-2-0 Göhler T (2006a) Profiluntersuchungen im Sandsteinbruch am Flügel Jägerhorn westlich Grillenburg 1. Beiträge zur Geologie der Sächsischen Kreide, BGSK-Info, 2006(1). https://bit.ly/31I46h0

Göhler T (2006b) Profiluntersuchungen im Sandsteinbruch am Flügel Jägerhorn westlich Grillenburg 2. Beiträge zur Geologie der Sächsischen Kreide, BGSK-Info, 2006(2). https://web.archive.org/https:// www.kreidegeologie.de/aufschluss_097_2.htm

Göhler T (2011) Die Sequenzgrenze zwischen Oberhäslich- und Dölzschen-Formation im alten „Quaderbruch“ nordöstlich Naundorf (Tharandter Wald). Beiträge zur Geologie der Sächsischen Kreide, BGSK-Info 2011(3-4): 26-33.

Götze J, Siedel H (2004) Microscopic scale characterization of ancient building sandstones from Saxony (Germany). Materials Characterization 53: 209-222. https://doi.org/10.1016/j.matchar.2004.08.016

Grüne Liga Osterzgebirge (2011) Tharandter Wald. Naturkundliche Wanderziele, Naturführer Ost-Erzgebirge 3, 2. Aufl.: 267-301.

Grüne Liga Osterzgebirge (2021a) FND Sandsteinbruch am Jägerhorn. https://osterzgebirge.org/de/natur-erkunden/schutzgebiete/naturdenkmale/flaechennaturdenkmale-fnd/fnd-sandsteinbruch-am-jaegerhorn

Grüne Liga Osterzgebirge (2021b) FND Buchen-Traubeneichen-Restbestockung bei Grillenburg. https://osterzgebirge.org/de/natur-erkunden/schutzgebiete/naturdenkmale/flaechennaturdenkmale-fnd/ fnd-buchen-traubeneichen-restbestockung-bei-grillenburg

Grunert S (1986) Der Sandstein der Sächsischen Schweiz. Abhandlungen des Staatlichen Museums für Mineralogie und Geologie zu Dresden 34: 155 S.; Leipzig.

Häntzschel W (1933) Das Cenoman und die Plenus-Zone der sudetischen Kreide. Abhandlungen der Preußischen Geologischen Landesanstalt, Neue Folge 150: 161 S.; Berlin. 
Häntzschel W (1934) Die Gliederung und Altersstellung der Crednerien-Schichten bei Niederschöna und Dippoldiswalde. Zeitschrift der Deutschen Geologischen Gesellschaft 86(10): 650-662.

Henckel JF (1722) Flora Saturnizans, die Verwandschaft des Pflanzen mit dem Mineral-Reich, etc.: 670 S.; Leipzig.

Herrmann O (1899) Steinbruchindustrie und Steinbruchgeologie, 1. Aufl.: 428 S.; Berlin.

Herrmann O (1916) Steinbruch-Industrie und Steinbruch-Geologie, 2. Aufl.: 312 S.; Berlin.

Horn G (1938) Die Serpulasande im alten Naundorfer Quaderbruch. Mitteilungen des Naturwissenschaftlichen Vereins e. V. zu Freiberg in Sachsen 3: 51-52.

Janetschke N, Wilmsen M (2014) Sequence stratigraphy of the lower Upper Cenomanian Elbtal Group (Cenomanian-Turonian of Saxony, Germany). Zeitschrift der Deutschen Gesellschaft für Geowissenschaften 165: 179-308. https://doi.org/10.1127/18601804/2013/0036

Janetschke N, Niebuhr B, Wilmsen M (2015) Inter-regional sequence stratigraphical synthesis of the Plänerkalk, Elbtal and Danubian Cretaceous groups (Germany): Cenomanian-Turonian correlations around the Mid-European Island. Cretaceous Research 56: 530-549. https://doi.org/10.1016/j.cretres.2015.04.007

Kantschew T (2010) Neues Jagdhaus in Grillenburg / Tharandt, „Heimatschutzstil“" während der NS-Zeit. In: Das Neue Dresden - Aufbruch und Erinnerung. https://www.das-neue-dresden.de/neue-tradition-wilhelm_jost.html

Krutzsch W (1966) Die sporenstratigraphische Gliederung der Oberkreide im nördlichen Mitteleuropa - Methodische Grundlagen und gegenwärtiger Stand der Untersuchungen. In: Diener I (Hrsg.) Stratigraphisches Korrelationsschema für die Kreide der Deutschen Demokratischen Republik und angrenzender Gebiete. Abhandlungen des Zentralen Geologischen Instituts 5: 111-137.

Martick S (1999) Aufnahme und Dokumentation der Lagerungsverhältnisse des Gebietes westlich des Kurortes Hartha zwischen Hartheberg und Borschelsberg (Blatt NW Tharandt, Nr.: 5047) im Maßstab 1:10.000. Diplomkartierung, TU Bergakademie Freiberg, Institut für Geologie.

Naumann CF, Cotta B (1845) Erläuterungen zu Section X der geognostischen Charte des Königreichs Sachsen und der angränzenden Länderabtheilungen, oder: Geognostische Skizze der Umgegend von Dresden und Meißen: 496 S.; Dresden.

Niebuhr B (2020) Pennrich-Formation. In: LithoLex (Online-Datenbank), Datensatz Nr. 10000070 vom 19.08.2020. Hannover: BGR. https://litholex.bgr.de

Niebuhr B (2021) Sandstein · Seestern · Saurier - Sachsen in der Kreidezeit: 228 S.; Museum der Westlausitz Kamenz.

Niebuhr B, Wilmsen, M. (2016) Ichnofossilien. In: Niebuhr B, Wilmsen M (Hrsg.) Kreide-Fossilien in Sachsen, Teil 2. Geologica Saxonica 62: 181-238.

Niebuhr B, Wilmsen, M (in Vorber.) The transgression history of the Saxonian Cretaceous revisited or: the imperative for a complete stratigraphic reappraisal (Cenomanian, Elbtal Group, Germany).

Niebuhr B, Hiss M, Kaplan U, Tröger K-A, Voigt S, Voigt T, Wiese F, Wilmsen M (2007) Lithostratigraphie der norddeutschen Oberkreide. Schriftenreihe der Deutschen Gesellschaft für Geowissenschaften 55: $136 \mathrm{~S}$; ; Hannover.

Niebuhr B, Schneider S, Wilmsen M (2014) Muscheln. In: Niebuhr B, Wilmsen M (Hrsg.) Kreide-Fossilien in Sachsen, Teil 1. Geologica Saxonica 60(1): 83-168.
Niebuhr B, Wilmsen M, Voigt T (2020) Die Oberkreide (Cenomanium-Mittelconiacium) im Zittauer Sandsteingebirge (Deutschland, Tschechien). Zeitschrift der Deutschen Gesellschaft für Geowissenschaften 171: 163-197. https://doi.org/10.1127/zdgg/2020/0223

Petrascheck W (1899) Studien über Faciesbildungen im Gebiete der sächsischen Kreideformation. Abhandlungen der Naturwissenschaftlichen Gesellschaft ISIS zu Dresden 1899: 31-84.

Pietzsch K (1912, 1914) Geologische Spezialkarte des Königreichs Sachsen. Blatt 81, Section Tharandt, Erläuterungen, 2. Aufl.: 125 S.; Leipzig.

Prescher H (1957) Die Niederschönaer Schichten der sächsischen Kreide. Freiberger Forschungshefte C 34: 1-96.

Reichert H (1961) Tharandter Wald und Umgebung von Tharandt - Exkursionstagebuch Nr. 3. Bergakademie Freiberg - Fernstudium: 54 S.; Freiberg.

Ruge S (1889) Die erste Landesvermessung des Kurstaates Sachsen, auf Befehl des Kurfürsten Christian I. ausgeführt von Matthias Oeder (1586-1607), zum 800jährigen Regierungs-Jubiläum des Hauses Wettin. Siebzehn kolorierte Karten in Lichtdruck. Deutsche Fotothek, SLUB, Karte 8: Aufnahme-Nr.: df_dk_0003959, Datensatz-Nr.: obj 70401425.

Sauer A (1886, 1887) Geologische Specialkarte des Königreichs Sachsen. Blatt 80, Section Freiberg. Erläuterungen, 1. Aufl.: 92 S.; Leipzig.

Sauer A $(1889,1891)$ Geologische Specialkarte des Königreichs Sachsen. Blatt 81, Section Tharandt. Erläuterungen, 1. Aufl.: 88 S.; Leipzig.

Sauer A (1899, 1900) Geologische Specialkarte des Königreichs Sachsen. Blatt 80, Section Freiberg. Erläuterungen, 2. Aufl.: 90 S.; Leipzig.

Schander H (1924) Die cenomane Transgression im mittleren Elbtalgebiet. Zeitschrift der Deutschen Geologischen Gesellschaft, Abhandlungen 75: 107-154.

Schiffner A (1940) Handbuch der Geographie, Statistik und Topographie des Königreiches Sachsen, Zweite Lieferung, den Dresdener Kreisdirektionsbezirk enthaltend. 714 S.; Leipzig.

Schmidt H (1838) Die Inspection Freiberg als dritte Abtheilung von Sachsens Kirchen-Galerie 2: 149-278.

Schreiter R (1927) Geologischer Führer durch das Erzgebirge: $331 \mathrm{~S}$; Freiberg.

Schulze CF (1769) Nachricht von den in der dreßdnischen Gegend vorhandenen Mineralien und Foßilien - Neues Hamburgisches Magazin, oder gesammleter Schriften, zum Unterricht und Vergnügen, aus der Naturforschung und den angenehmen Wissenschaften überhaupt 33: $195-232$.

Seilacher A (1967) Bathymetry of trace fossils. Marine Geology 5(3): 224-229. https://doi.org/10.1016/0025-3227(67)90051-5

Süß J, Weicker G (1923) Rings um Dresden in 15 Tagen. Sächsische Wanderbücher: 147 S., Dresden.

Siedel H, Götze J, Kleeberg K, Palme G (2011) Bausandsteine in Sachsen. In: Ehling A, Siedel H (Hrsg.) Bausandsteine in Deutschland 2: Sachsen-Anhalt, Sachsen, Schlesien (Polen), 163-272.

Tröger K-A (1969) Zur Paläontologie, Biostratigraphie und faziellen Ausbildung der unteren Oberkreide (Cenoman bis Turon) Teil II: Stratigraphie und fazielle Ausbildung des Cenomans und Turons in Sachsen, dem nördlichen Harzvorland (subherzyne Kreide) und dem Ohm-Gebirge. Abhandlungen des Staatlichen Museums für Mineralogie und Geologie zu Dresden 13: 1-70.

Tröger K-A, Prescher H (1963) Exkursion 8, Elbsandsteingebirge. Geologische Gesellschaft in der Deutschen Demokratischen Republik, 
Führer zu den Exkursionen 1-14 anläßlich der 10. Jahrestagung vom 13. bis 18. Mai 1963 in Leipzig, 151-166.

Umweltportal Sachsen (2020): Interaktive Karte ,Schutzgebiete in Sachsen“ (iDA). https://www.natur.sachsen.de/schutzgebiete-in-sachsen7050.html

Voigt S, Gale AS, Voigt T (2006) Sea-level changes, carbon cycling and palaeoclimate during the Late Cenomanian of northwest Europe; an integrated palaeoenvironmental analysis. Cretaceous Research 27: 836-858. https://doi.org/10.1016/j.cretres.2006.04.005

Voigt T (1994) Faziesentwicklung und Ablagerungssequenzen am Rand eines Epikontinentalmeeres - Die Sedimentationsgeschichte der Sächsischen Kreide. Doktorarbeit, TU Bergakademie Freiberg, Fakultät für Geowissenschaften, Geotechnik und Bergbau.

Voigt T (1998) Entwicklung und Architektur einer fluviatilen Talfüllung - die Niederschöna Formation im Sächsischen Kreidebecken. Abhandlungen des Staatlichen Museums für Mineralogie und Geologie zu Dresden 43/44: 121-139.

Voigt T, Voigt S, Tröger K-A (1994) Fazies-Entwicklung einer ertrunkenen Felsküste - die obercenomane Monzonitklippe westlich von Dresden. Freiberger Forschungshefte C 452: 23-34.

Wagner P (1930) Erdgeschichtliche Natururkunden aus dem Sachsenlande. Landesverein Sächsischer Heimatschutz: 195 S.; Dresden.

Walter H, Suhr P (1997) Proximale Tempestite aus dem tiefen Obercenoman (naviculare-Zone) von Dresden-Coschütz. Freiberger Forschungshefte C 468: 305-317.
Weber, J (2020) Das Geotop „Sandsteinbruch am Flügel Jägerhorn“ auf dem Weg zum Nationalen Geotop? Geopark-Newsletter 3/2020: 9-10.

Wilmsen M (2017) Macroinvertebrate fauna and depositional environment of the lower Upper Cenomanian Oberhäslich Formation in the Saxonian Cretaceous Basin (Germany). Annales de Paléontologie 103: 33-44. https://doi.org/10.1016/j.annpal.2016.11.003

Wilmsen M, Bansal U (2021) Depositional setting and limiting factors of early Late Cretaceous glaucony formation: implications from Cenomanian glauconitic strata (Elbtal Group, Germany). Facies 67(24). https://doi.org/10.1007/s10347-021-00627-y

Wilmsen M, Vodrážka R, Niebuhr B (2011) The Upper Cenomanian and Lower Turonian of Lockwitz (Dresden area, Saxony, Germany): lithofacies, stratigraphy and fauna of a transgressive succession. Freiberger Forschungshefte C 540: 27-45.

Wilmsen M, Niebuhr B, Fengler M, Püttmann T, Berensmeier M (2019) The Late Cretaceous transgression in the Saxonian Cretaceous Basin (Germany): old story, new data and novel findings. Bulletin of Geosciences 94: 71-100. https://doi.org/10.3140/bull.geosci.1723

Wilmsen M, Niebuhr B, Kennedy WJ (2022) Middle Cenomanian ammonites from the Oberhäslich Formation (Elbtal Group, Germany): stratigraphic and palaeogeographic implications for the Saxo-Bohemian Cretaceous. Neues Jahrbuch für Geologie und Paläontologie [eingereicht]. 